\title{
Mecanismos envolvidos na cicatrização: uma revisão
}

\author{
Carlos Aberto Balbino, Leonardo Madeira Pereira, Rui Curi*
}

Departamento de Fisiologia e Biofísica, Instituto de Ciências Biomédicas, Universidade de São Paulo

*Correspondência:

Departamento de Fisiologia e Biofísica, Instituto de Ciências Biomédicas, Universidade de São Paulo, Av. Prof. Lineu Prestes, 1524, Butantan 05508-900 São Paulo, SP, Brasil E-mail: ruicuri@fisio.icb.usp.br
Os mecanismos envolvidos no processo de reparo de tecidos estão revisados nesse trabalho. O processo de cicatrização ocorre fundamentalmente em três fases: inflamação, formação de tecido de granulação e deposição de matriz extracelular e remodelação. Os eventos celulares e tissulares de cada uma dessas fases estão descritos e discutidos. Os mediadores químicos estão correlacionados com os eventos do processo de cicatrização e as células envolvidas. Especial ênfase é dada à participação dos fatores de crescimento.
Unitermos

- Cicatrização

- Leucócitos

- Fibroblastos

- Queratinócitos

- Plaquetas

- Fatores de crescimento

- Citocinas

\section{INTRODUÇÃO}

A capacidade auto-regenerativa é um fenômeno universal nos organismos vivos. Nos organismos unicelulares, esta restrita à presença de enzimas responsáveis pela recuperação de elementos estruturais (como os constituintes do citoesqueleto, membranas e paredes celulares) e de moléculas de alta complexidade (como proteínas de elevada complexidade estrutural, RNAs e o DNA). Em organismos superiores, além destes, também ocorre o reparo de tecidos que pode se dar de duas formas: (1) pela regeneração com a recomposição da atividade funcional do tecido ou (2) pela cicatrização com restabelecimento da homeostasia do tecido com perda da sua atividade funcional pela formação de cicatriz fibrótica.

Danos tissulares de qualquer natureza (física, química ou biológica) desencadeiam de imediato uma série de eventos que de forma simplista se traduzem como rubor, tumor, calor e dor. Estes sinais resultam da ativação de células nervosas, estromais, vasculares e circulatórias por estímulos físicos ou por sinalização química feita por estruturas das células rompidas (porções da membrana celular e organelas), fragmentos dos elementos inertes dos tecidos (colágenos, elastinas, fibronectinas, e outros), proteí- nas séricas que extravasam dos vasos rompidos e por ação de mediadores inflamatórios pré-formados (liberados principalmente dos grânulos das plaquetas, mastócitos e terminações nervosas periféricas) ou neo-sintetizados (eicosanóides e PAF)(Contran et al., 2001). Essas moléculas, ao se ligarem a receptores localizados na superfície da membrana das células locais, induzem profundas modificações no seu metabolismo, na expressão de genes e conseqüentemente em seu fenótipo. Como resposta, observa-se a produção de uma segunda onda de mediadores de natureza lipídica (eicosanóides) e peptídica (citocinas, fatores de crescimento e neuropeptídeos) e a externalização de proteínas de adesão para leucócitos, nas células endoteliais na superfície da membrana voltada para a luz dos vasos. Além disso, como decorrência do próprio trauma ou da ativação celular, o microambiente tem sua composição físico-química alterada (baixa tensão de $\mathrm{O}_{2}$, diminuição de $\mathrm{pH}$, presença de espécies reativas de nitrogênio e oxigênio) sendo esta também uma outra forma de sinalização que ativa as células envolvidas no reparo tissular.

$\mathrm{Na}$ continuidade do processo, ocorrem no tecido lesado a infiltração de células circulantes (neutrófilos e monócitos) e a migração de células das áreas adjacentes como células epiteliais, queratinócitos e fibroblastos. Es- 
tas últimas, em cooperação com as células locais, anteriormente ativadas, serão as protagonistas da fibroplasia (produção de colágeno pelos fibroblastos) e deposição de matriz extracelular, angiogênese (formação de novos vasos), cicatrização e reepitelização da região da ferida (Singer, Clark, 1999). Clark (1993) dividiu o reparo em três fases: (1) inflamação, (2) formação de tecido de granulação com deposição de matriz extracelular e (3) remodelação. Segundo ele, estas não são mutuamente excludentes, mas sobrepostas no tempo. O reparo completo de tecidos resulta de alternâncias sucessivas de reações anabólicas e catabólicas que têm os leucócitos como um de seus mais importantes protagonistas. Essas células, além de suas conhecidas atividades imunes, estão intimamente envolvidas com as reações catabólicas de degradação de tecidos pela produção de proteases e espécies reativas de oxigênio e nitrogênio e também com as reações anabólicas de formação de tecidos pela produção de fatores de crescimento (Riches, 1996), reponsáveis pela recomposição da celularidade regional ou restabelecimento da sua homeostasia pela formação da cicatriz.

\section{DINÂMICA DAS FASES DO PROCESSO DE REPARO}

Na divisão do processo de reparo em três fases, são considerados, prioritariamente, os aspectos macroscópicos e histológicos predominantes em cada uma delas. Nessa forma de visão e descrição do processo, torna-se secundário o fato de que as características assumidas pela lesão, ao longo de sua evolução, resultam da sucessão ou sobreposição de eventos celulares e tissulares resultantes da ativação celular por mediadores químicos. Assim, na primeira parte desse trabalho, está descrita a dinâmica dos eventos responsáveis pela característica de cada uma das fases e, na segunda, a influência dos mediadores químicos em cada um desses eventos.

\section{Fase Inflamatória}

A maioria das formas de lesão a que os organismos vivos estão sujeitos leva a alterações nas junções e/ou nas células endoteliais. Em alguns casos, ocorre ruptura de vasos sanguíneos e o extravasamento de seus constituintes. Os eventos iniciais do processo de reparo estão, nos primeiros momentos, voltados para o tamponamento desses vasos. Quase concomitante ao estímulo lesivo, e devido à influência nervosa (descargas adrenérgicas) e ação de mediadores oriundos da desgranulação de mastócitos, ocorre vasoconstrição como primeira resposta. A injúria do endotélio (ruptura, fissura ou erosão) dispara uma seqüên- cia de eventos, iniciando-se com a deposição das plaquetas, prosseguindo com sua ativação e posterior recrutamento de novas plaquetas. O resultado dessa seqüência é a formação de um trombo rico em plaquetas, que provisoriamente tampona a lesão endotelial (Lefkovits et al., 1995). Esse trombo rico em plaquetas (trombo branco) é rapidamente infiltrado pela fibrina, transformando-se em um trombo fibrinoso. Logo após, os eritrócitos são capturados por essa rede fibrinosa e forma-se então o trombo vermelho, principal responsável pela oclusão do vaso sangüíneo rompido (Davies, 1990). Este, além de limitar a perpetuação da perda de constituintes circulatórios para os interstícios celulares, fornece uma matriz preliminar, que alicerçará a migração das células responsáveis pelo desencadeamento do processo de reparo. A adesão inicial das plaquetas à superfície lesada ocorre pelas proteínas de adesão presentes na sua membrana. As principais delas são os receptores da glicoproteína IIb/IIIa (GP IIb/ IIIa). Esse receptor possui sítios de ligação para o fibrinogênio, fator de von Willebrand, vitronectina, fibronectina e trombospondina. Embora seja membro da família de receptores das integrinas (responsáveis pela interação e adesão célula-célula), a GP IIb/IIIa possui uma distribuição restrita sendo encontrada apenas nas plaquetas e em outras células de linhagem megacariocítica. É a proteína mais abundante da superfície plaquetária, com aproximadamente 80.000 cópias por plaqueta (Wagner et al., 1996), representando 1 a $2 \%$ de todas as proteínas plaquetárias (Jennings, Phillips, 1982). Em seguida, as plaquetas são ativadas por um grande número de substâncias agonistas presentes na matriz subendotelial e na corrente sangüínea. O colágeno subendotelial exposto pela ruptura do vaso e a trombina gerada pelos processos de coagulação são fortes agonistas da ativação e agregação plaquetárias (Davies, 1990; Lefkovits et al., 1995; Ambrose, 1996; Amos, 1996). Além disso, a plaqueta ativada aumenta a ação da protrombinase, que promove maior produção da trombina, a partir da protrombina, criando assim, condições para a amplificação da adesão plaquetária. O ADP liberado das hemácias e grânulos densos das próprias plaquetas é outro elemento amplificador da agregação das plaquetas. Este induz nelas a exposição do receptor GP IIb/IIIa ao fibrinogênio e fator de von Willebrand (Lefkovits et al., 1995; Willerson, 1995; Coe1ho, 1998). Contribuindo também para a agregação plaquetária, o ácido araquidônico da membrana das plaquetas em processo de agregação, é convertido em $\mathrm{TxA}_{2}$ pelas enzimas ciclooxigenase e tromboxane sintetase. $\mathrm{O}$ TxA $\mathrm{A}_{2}$, além de forte agonista da agregação plaquetária, é um potente vasoconstritor e, também, indutor da exposição dos sítios de ligação da GP IIb/IIIa ao 
fibrinogênio e fator de von Willebrand. A sua forma de ação, na indução da exposição dos sítios de ligação da GP IIb/IIIa, difere dos mediadores anteriores por se dar por mecanismo dependente da mobilização do cálcio intracelular. Outro importante derivado do araquidonato, que é liberado por macrófagos e mastócitos, plaquetas e outras células ativadas, é o PAF. Este é um ativador importante de plaquetas e indutor da sua agregação. Como agonistas da agregação plaquetária, podem também ser citadas a noradrenalina e a serotonina (Lefkovits et al., 1995; Coller, 1982). Esses mediadores estimulam diferentes cascatas de ativação plaquetária, porém, a via final comum a todos é a ativação do receptor da GP IIb/IIIa que pela interação com o fator de von Willebrand e o fibrinogênio é o verdadeiro efetor da agregação e ativação plaquetárias.

As plaquetas ativadas liberam fatores de crescimento como o TGF- $\beta$ e o PDGF, quimiocinas como o CTAPIII e também outras proteínas como fibrinogênio, fibronectina e tromboplastina que são encontradas em seus grânulos. A interação das proteínas dos grânulos plaquetários com proteínas da matriz extracelular somados à massa de corpos plaquetários agregados, ao se estabilizarem, formam uma matriz provisória. Esta se torna mais consistente à medida que a fibrina se polimeriza pelas vias intrínsica ou extrínsica da coagulação.

Os mediadores liberados pelas plaquetas ativadas, como TGF- $\beta$, PDGF (Dyson, 1990), tromboxanos e PAF se difundem pela matriz provisória formando um gradiente quimiotático que orienta a migração das células (tanto da circulação como das regiões adjacentes) envolvidas com a instalação da resposta inflamatória.

Uma vez que os neutrófilos são as células mais abundantes no sangue, um número significativo deles é passivamente coletado pelo trombo provisório durante o rompimento dos vasos. Após este extravasamento passivo, os neutrófilos migram para a superfície da ferida para formar uma barreira contra a invasão de microorganismos e promover o recrutamento ativo de mais neutrófilos a partir dos vasos adjacentes não lesados (Foxman et al., 1997; Engelhard et al., 1998). Ao final de um dia após a lesão eles constituirão 50\% das células migradas ao local (Engelhard, 1998).

Além dos mediadores liberados durante a agregação plaquetária, o recrutamento de mais neutrófilos é influenciado também por quimiocinas produzidas pelos neutrófilos coletados pelo trombo provisório. No interior dessas células, o CTAP-III é proteoliticamente convertido em NAP2 que, após a conversão, é exportado para o microambiente (Brandt et al., 2000). Por influência dos mediadores liberados localmente, as células associadas aos vasos (célu- las endoteliais e periócitos) são ativadas e passam a secretar dentre outros mediadores o GRO-a que é um promotor do processo de diapedese de neutrófilos (Goebeler et al., 1998). A quimiotaxia de neutrófilos é ainda sustentada nestes primeiros momentos pelo ENA-78 expresso nas células mononucleares presentes na matriz provisória. O reconhecimento das três quimiocinas (NAP2, GRO- $\alpha$ e ENA-78) pelos neutrófilos se dá via CXCR2 presente na membrana celular (Brandt, 2000; Murdoch \& Finn, 2000; Rossi, Zlotnik, 2000). O influxo de neutrófilos, nestes primeiros momentos, provavelmente também já estará sendo mediado por leucotrienos liberados das células ativadas do trombo provisório.

A primeira contribuição de mediadores circulantes para a formação do gradiente quimiotático vem de proteínas plasmáticas como o Fator de Hageman e o cininogênio de alto peso molecular. Da interação entre estas duas moléculas é gerada a bradicinina que, além de propriedades vasoativas e nociceptivas (geradoras de dor), é também indutora da metabolização do ácido araquidônico para eicosanóides. As moléculas desta família possuem importância comprovada em vários fenômenos inflamatórios e dentre eles a atividade quimiotática. Outros produtos oriundos da circulação que participam da formação do gradiente são as frações livres do Complemento, principalmente a C5a. Além da ação quimiotática direta desta molécula, a sua ligação a receptores localizados na superfície dos mastócitos, ativa-os para a produção de eicosanóides e liberação do conteúdo de seus grânulos, composto por várias moléculas com atividades pró-inflamatórias. Aúltima contribuição para a formação do gradiente quimiotático nestes momentos iniciais da resposta inflamatória são os produtos da fibrinólise. Durante o processo de formação do trombo definitivo, ocorre a proteólise da rede de fibrina. Os produtos de sua degradação são fortes agentes quimiotáticos para leucócitos (Huybrechts-Godin et al., 1979). À medida que ocorrem as primeiras migrações de células inflamatórias para o local, o gradiente é retroalimentado positivamente. As células que migram em resposta ao gradiente químico (neutrófilos, monócitos e fibroblastos), também, são em sua maioria produtoras de substâncias quimiotáticas com papel destacado para os eicosanóides e, principalmente, para as quimiocinas.

A produção e liberação dos mediadores acima descritos são isoladamente insuficientes para o recrutamento de neutrófilos a partir da circulação. A força de arraste da corrente circulatória impede seu contato com as paredes dos vasos. Por ação dos eicosanóides (leucotrienos, tromboxanos e prostaglandinas), citocinas (principalmente IL-1 e TNF $\alpha$ ) produzidas por macrófagos, mastócitos, células estromais e outros mediadores, as células 
endoteliais dos vasos não lesados são induzidas a expressarem em sua membrana proteínas de adesão para leucócitos (Gerszten et al., 1999). A expressão de integrinas ocorre por externalização das mesmas via corpúsculo de Weibel-Palade e/ou pela síntese de novas moléculas de integrinas, especialmente quando estão presentes IL-1 e TNF $\alpha$. Estas, em situações normais encontram-se internalizadas e, após a influência destes mediadores, são expressas na região de sua membrana voltada para o leito vascular. Também por ação desses mediadores inflamatórios, os capilares de vasos não lesados se dilatam. Isto lentifica a circulação sanguínea e diminui a sua força de arraste permitindo, assim, a marginação dos leucócitos e sua ligação às moléculas de adesão expressas nas células endoteliais. Na dependência do estímulo, outros tipos celulares podem predominar, desde eosinófilos (reações de hipersensibilidade) até macrófagos.

Com este último evento fica concluída a condição básica para a migração de células para a região lesada, ou seja: (1) existe uma matriz provisória que serve de alicerce para a migração celular (tanto a partir da circulação como das regiões adjacentes) formada pelos corpos de plaquetas agregadas e proteínas dos seus grânulos, proteínas da matriz extracelular e proteínas do sistema de coagulação; (2) embebidos nesta matriz há um gradiente de moléculas com propriedades quimioatrativas com concentração crescente em direção à lesão que orienta o sentido da migração celular, (3) a força de arraste da corrente sanguínea sobre as células circulatórias está diminuída devido à vasodilatação local e (4) estão expressas na superfície das células endoteliais, dos vasos não lesados, as moléculas de adesão que ancoram os leucócitos circulantes e permitem a sua transmigração pelo endotélio.

Os neutrófilos oriundos da circulação são as primeiras células a alcançarem a região inflamada, sendo os tipos celulares predominantes entre o primeiro e segundo dias. Sua função principal neste processo é de eliminação de possíveis microorganismos pela fagocitose. Como a saturação de mediadores quimiotáticos dirigidos para um mesmo receptor torna a célula em migração irresponsiva a este e leva à regulação negativa de sua expressão na membrana (Murdoch, Finn, 2000), os neutrófilos oriundos da circulação, após a diapedese, cessam a migração passando a residir difusamente no coágulo. Isso ocorre porque, até este momento, as concentrações de NAP-2, GRO- $\alpha$ e ENA-78 (todos ligantes do receptor CXCR2) são muito superiores a concentração dos demais quimioatraentes. A irresponsividade temporária dos neutrófilos pelo receptor CXCR2, é possivelmente superada pela expressiva e seletiva produção de IL-8 abaixo da superfície da ferida. Devido a IL-8 também estimular o receptor CXCR1, além do CXCR2, dos neutrófilos, esta é capaz de desencadear uma segunda resposta migratória dirigida para a profundidade da ferida (Murdoch, Finn, 2000). É interessante assinalar que a explosão respiratória (ou do inglês respiratory burst) depende da interação da IL-8 exclusivamente com o CXCR1 em detrimento ao CXCR2 (Jones et al., 1996). As próximas células que surgem na região são os macrófagos derivados de monócitos (segundo ao quinto dia) que, ao contrário do papel desempenhado pelos neutrófilos, é o elemento mais crítico na indução do processo de reparo (Di Pietro, 1995). Além de auxiliar os neutrófilos na eliminação de microorganismos pela fagocitose, após fagocitá-los e processá-los nos fagossomas, apresenta seus peptídios pelo complexo maior de histocompatibilidade (MHC) às células T auxiliares (Riches, 1996; Di Pietro, 1995). Desta forma, a fagocitose destas células atua como elo entre o sistema imune inato e o adaptativo. Além disso, é a célula mais eficiente na eliminação de fragmentos teciduais inclusive removendo pela fagocitose os neutrófilos que perderam função (Newman et al., 1992). Ainda, por influência de ligantes a seus receptores de membrana, os macrófagos produzem e exportam mediadores lipídicos (eicosanóides), mediadores peptídicos (citocinas e fatores de crescimento), outras proteínas (tais como frações do complemento e fatores de coagulação) e enzimas relacionadas ao reparo (tais como colagenases, matriz de metaloproteases). Além da ativação por ligantes, os macrófagos podem ser também ativados por alterações físico-químicas do microambiente. Nas regiões distais onde os vasos se romperam, o aporte de oxigênio fica comprometido em função da formação do trombo. O influxo de neutrófilos e macrófagos ativados para esta região aumenta a demanda por oxigênio com conseqüente elevação das concentrações de ácido láctico e queda do pH. Esta combinação, hipóxia, $\mathrm{pH}$ baixo e alta concentração de ácido láctico, ativa o macrófago para a produção de fatores de crescimento.

\section{Fase Fibroblástica e de Deposição de Matriz Extracelular}

Com a presença local de macrófagos derivados de monócitos e a produção e liberação dos mediadores químicos produzidos por eles, a migração e ativação de fibroblastos é intensificada. Essas células são os principais componentes do tecido de granulação e após a influência dos fatores de crescimento e demais mediadores, derivados principalmente (mas não exclusivamente) dos macrófagos, são ativadas e migram das margens da ferida para o seu centro. Isto se dá pela matriz provisória formada e seguindo a orientação do gradiente químico de 
substâncias quimioatraentes. Com o aumento do número de fibroblastos ativados para a produção de colágeno no local, a matriz extracelular começa a ser substituída por um tecido conjuntivo mais forte e mais elástico. Este processo é denominado de fibroplasia e para a sua eficiência é necessária a ocorrência em paralelo da formação de novos vasos sangüíneos, ou seja, é necessária a neovascularização da região. Além da ação direta de fatores de crescimento sobre as células da vasculatura, a indução da angiogênese é, em parte, creditada à baixa tensão de oxigênio característica que ocorre no centro de uma ferida (Knighton et al., 1981).

Com a fibroplasia se inicia a formação do tecido de granulação (por volta do quarto dia) (Guidugli-Neto, 1987) composto por macrófagos, fibroblastos e vasos neoformados que estão suportados por uma matriz frouxa de fibronectina, ácido hialurônico e colágeno tipos I e II (Guidugli-Neto, 1992). Este tecido é edematoso e caracterizado pela presença de muitos espaços vazios, devido à imaturidade dos vasos, os quais, são extremamente exudativos e sangram com facilidade. Ao serem observados a olho nu, a superfície deste tecido parece conter muitos grânulos. Na verdade, estes nada mais são que as extremidades rombas de vasos neoformados que estão organizados perpendicularmente em direção à superfície e possuem uma coloração vermelha escura. A neovascularização é essencial neste estágio porque permite a troca de gases e a nutrição das células metabolicamente ativas (Eckersley, Dudley, 1988). Sob estímulo de fatores de crescimento e de outros mediadores, as células endoteliais do interior de capilares intactos nas margens da ferida passam a secretar colagenase e ativador do plasminogênio. Essas substâncias promovem aberturas na membrana basal e permite a migração das células endoteliais que, atravessando a parede do vaso e utilizando como substrato a matriz extracelular provisoriamente produzida, seguem em direção à região da lesão. Uma vez na região externa do vaso, elas passam pelo processo de diferenciação para aquisição da capacidade de formação de novos tubos capilares. As células endoteliais migratórias formam no exterior do vaso um broto capilar que em seguida une-se ao capilar de onde eram originárias para o restabelecimento do fluxo sangüíneo (Rudolph \& Ballantyne, 1990).

Todo processo lesivo promove a perda de massa de tecido. O leito de uma ferida aberta necessita ser preenchido e para isto são operadas duas estratégias diferentes. Na primeira, a própria natureza anatômica da ferida proporciona um estímulo para a migração e proliferação das células (fibroblastos, células epiteliais e queratinócitos) a partir das suas margens. Por um fenômeno denominado por Montesano e Orci (1988) de "efeitos de vizinhança li- vre", as células basais próximas à região da ferida, ao perderem a interação com as células adjacentes, são ativadas, adquirem propriedades mitóticas e proliferam em direção ao centro da lesão. Na segunda, mesmo quando o espaço da lesão está preenchido por tecido de granulação, as margens se movem uma em direção à outra, como se houvesse uma força de tração invisível (Peacock, 1984). Isto ocorre devido a diferenciação de alguns fibroblastos das margens da ferida para miofibroblastos, portanto, para fibroblastos com capacidade contrátil, a ser discutido em mais detalhe adiante.

Com a evolução do processo, a matriz extracelular, que inicialmente era composta principalmente por proteínas derivadas de plaquetas e do plasma, passa por modificações em sua composição. A migração e ativação de macrófagos e fibroblastos para a região, somada à presença de vasos neoformados, permitem que os componentes da nova matriz extracelular passem a ser localmente produzidos principalmente por estas células. Os fibroblastos passam a depositar grandes quantidades de fibronectina que, embora seja substrato que desempenha outras funções, basicamente serve para a fixação da própria célula. Outra substância produzida em grande quantidade neste segundo estágio é o ácido hialurônico, um polissacarídeo glicosaminoglicano não sulfatado com facilidade de se ligar à água, que auxilia na resistência do tecido à compressão. Estas duas substâncias predominam na matriz durante as primeiras fases do reparo pois esta combinação propicia um microambiente eficiente para a movimentação das células, necessárias nesta etapa. À medida que o processo de maturação da ferida avança, a concentração de ácido hialurônico diminui e aumenta a síntese de proteoglicanos ou glicosaminoglicanos sulfatados. Essa modificação na composição da matriz extracelular favorece a fixação e imobilidade das células favorecendo a diferenciação delas para fenótipos mais maduros. As células endoteliais dos vasos neoformados se diferenciam em células de revestimento e os vasos neoformados assumem as características funcionais de capilares. Os fibroblastos são as células que passam por mudanças fenotípicas mais acentuadas. Do fenótipo de células imaturas migratórias e replicativas no início do processo, passam para fenótipo característico de células ativamente engajadas na síntese protéica, ou seja, o seu citoplasma se torna volumoso e apresenta um retículo endoplasmático rugoso abundante. Com isto, eles passam a secretar grandes quantidades de colágeno. Este aos poucos substitui os proteoglicanos e a fibronectina até se tornar o principal componente da cicatriz em formação.

A tensão de oxigênio é um importante mecanismo de regulação do processo de reparo. No início do processo, a baixa tensão servia como estímulo ao macrófago para a 
produção de fatores de crescimento, para a migração e proliferação centrípeta das células das margens da ferida e indutor da angiogênese. Já nesta etapa, é necessária uma alta tensão de oxigênio para a hidroxilação dos resíduos de prolina e lisina nas cadeias polipeptídicas do colágeno montadas no citoplasma dos fibroblastos. Isto é proporcionado pela rede capilar neoformada.

Durante a fixação dos fibroblastos e seu amadurecimento fenotípico para células produtoras de colágeno, o processo de contração da ferida alcança a sua eficiência máxima. Isto ocorre devido à mudança de fenótipo dos fibroblastos das margens da ferida para miofibroblastos. Em um processo inicialmente descrito por Gabbiani et al. (1970), os fibroblastos destas regiões marginais começam a exibir características funcionais similares às células do músculo liso. Majno, Joris (1996) relataram que os miofibroblastos são células intermediárias entre musculares lisas e fibroblastos. Apesar de seu mecanismo contrátil estar ainda por ser esclarecido, estas células são encontradas alinhadas ao redor de depósitos da nova matriz extracelular, fazendo uniões célula a célula e gerando força de tensão. Auxilia também no processo de contração da ferida o ressecamento da sua crosta superficial que durante a desidratação diminui de tamanho e arrasta o tecido a ela aderido.

O processo de reepitelização da ferida se inicia imediatamente após a lesão pelo mecanismo de "efeitos de vizinhança livre". Células primitivas da camada basal do tecido epidermal possuem potencial mitótico latente. Em tecidos normais, este se encontra inibido pelo contato existente entre as células pela "inibição por contato". Com a ocorrência de uma lesão, este mecanismo inibitório desaparece e as células entram imediatamente em processo mitótico. A ineficiência e dificuldade de constatação do processo mitótico destas células nas etapas iniciais são devidas à, ainda, inexistência de um substrato adequado para isto na região da ferida. Este somente é fornecido quando o tecido de granulação alcança o nível da epiderme. Além do fator margens livres, contribui para o processo de reepitelização EGF cujos mecanismos de ação estão detalhadamente descritos adiante. Quando ativadas, as células epidermais retraem os tonofilamentos intracelulares, ocorre a dissolução dos desmossomas intercelulares e na periferia do interior da célula se formam filamentos de actina. Estas alterações liberam-nas da membrana basal e das células epiteliais adjacentes, permitindo assim, sua movimentação em direção ao centro da ferida. As células migram sobre a matriz celular provisória e, durante sua trajetória, segue depositando quantidades apreciáveis de fibronectina. A superfície da ferida umedecida e oxigenada é um fator que acelera o processo de migração. Quando estas células encontram uma crosta recobrindo a região lesada, promovem uma dissecação entre esta e a matriz, porém, às custas de um retardo de velocidade de migração. À medida que a região da lesão vai sendo coberta pelas células epidermais é acionado o mecanismo de "inibição por contato". As células voltam a apresentar o fenótipo original, a membrana basal é refeita e os hemidesmossomos e desmossomos são reconstituídos.

Ao final desta etapa, o leito da ferida está totalmente preenchido pelo tecido de granulação, a circulação é restabelecida pela neovascularização e a rede linfática está passando por regeneração. Lentamente o tecido de granulação é enriquecido com mais fibras colágenas o que começa a dar à região lesada a aparência de cicratriz devido ao acúmulo de massa fibrosa (Guidugli-Neto, 1987).

\section{Fase de Remodelamento}

Por volta do décimo dia, o leito da ferida está totalmente preenchido pelo tecido de granulação (GuidugliNeto, 1987), com uma rede capilar atravessado-o e, a rede linfática em franca regeneração, devido a sua reconstrução ter início posterior ao da vasculatura. O tecido de granulação vai sendo enriquecido com mais fibras de colágeno e começa a adquirir a aparência de massa fibrótica característica da cicatriz. Nesta etapa, surgem as primeiras fibras de colágeno tipo I (Clark, Henson, 1988). Com a evolução do processo, acentua-se a deposição de colágeno e a maioria das células desaparecem (observase a apoptose de fibroblastos e células endoteliais) formando finalmente a cicatriz. É consenso atualmente, que a resolução completa de uma ferida, somente pode ser considerada após concluída a maturação e remodelagem da matriz extracelular. Este processo ocorre lentamente levando muitos meses ou às vezes anos e, mesmo assim, uma cicatriz cutânea completamente madura possui apenas $70 \%$ da resistência da pele normal.

Os eosinófilos aparecem nas últimas fases da reparação e presumi-se que podem estar relacionados à produção de fatores de crescimento (Todd et al., 1991). Quando a ferida completou o seu fechamento e os microorganismos foram eliminados, os linfócitos constituem o subsistema leucocitário mais abundante em feridas humanas (Engelhard et al., 1998). Os linfócitos não somente são efetores imunes, mas também, produtores de fatores de crescimento (Blotnik et al., 1994). De forma notável, nesta etapa, eles são atraídos para a região da ferida em igual número que os monócitos e, a partir do décimo quarto dia, são os leucócitos que predominam na região (Blotnik et al., 1994).

A resistência de uma cicatriz é dada pela quantidade de colágeno depositada e pela forma com que as fibras 
estão organizadas. Quanto maior o número de ligações covalentes transversais, maior a resistência da cicatriz. Quando secretado na forma de tropocolágeno, as ligações transversais das fibras se dão por pontes de hidrogênio. No processo de amadurecimento da fibra, as lisinas, hidroxilisinas e lisinas glicosiladas constituintes da molécula de tropocolágeno são oxidadas até aldeídos pela enzima lisiloxidase. Estes, após a oxidação, se ligam covalentemente com outros grupos aldeídos ou com lisinas não oxidadas, o que aumenta a resistência da fibra.

O processo de remodelamento da cicatriz envolve etapas sucessivas de produção, digestão e orientação das fibrilas de colágeno. A deposição de colágeno é feita a princípio de maneira aleatória tendo como orientação a organização da fibronectina e dependente da natureza e direção das tensões aplicadas ao tecido. Essas fibras são subseqüentemente digeridas pela colagenase, ressintetizadas, rearranjadas de acordo com a organização das fibras do tecido conjuntivo adjacente e lateralmente ligadas por ligações covalentes. Essas ligações são formadas entre moléculas de tropocolágeno no âmbito da fibrila e entre as próprias fibrilas. Repetições sucessivas da lise, ressíntese, redirecionamento e religação formam fibras maiores de colágeno e resultam numa configuração mais regular da cicatriz. Isso aumenta a sua resistência devido à organização das fibras acompanhar as forças mecânicas a que o tecido está sujeito durante a atividade normal (Clark, 1985).

Ao final desta etapa, os anexos da pele, como folículos pilosos e glândulas sofrem regeneração limitada e a coloração da cicatriz permanece pálida, pois a regeneração dos melanócitos é deficiente (Johnston, 1990) e as cicatrizes são hipo-vascularizadas devido ao desaparecimento dos neocapilares.

\section{Principais mediadores químicos e seus efeitos no processo de reparo}

Durante a evolução do processo de reparo, os eventos que se sucedem são a infiltração de neutrófilos, infiltração de macrófagos, fibroplasia e deposição de matriz extracelular, angiogênese, cicatrização e reepitelização. Apesar deles estarem distribuídos nas três fases descritas, suas peculiaridades e particularidades permitem que recebam abordagem individual. Na regulação destes eventos estão envolvidos mediadores derivados da circulação (as frações livres do complemento, fatores de coagulação, moléculas do sistema fibrinolítico e hormônios como os esteroidais, tireoideanos e a insulina), cininas (histamina, bradicinina e serotonina), mediadores peptídicos (citocinas, fatores de crescimento, neuropeptídeos e estru- turas da matriz extracelular) e mediadores lipídicos (eicosanóides e PAF). Observa-se entre eles uma grande diversidade de natureza química, fontes produtoras e forma de influência sobre as células. A concentração elevada de alguns mediadores da fase de inflamação até a de remodelação demonstra a existência de interdependência destes para um mesmo evento. A redundância de efeitos também pode ser observada em outras situações. Por vezes, a ausência de um determinado mediador é compensada pelo aumento das concentrações de outro com atividade semelhante. Por outro lado, alguns mediadores são críticos para um determinado evento e sua ausência termina por comprometer seriamente o reparo de tecidos. Assim, para melhor entendimento do processo como um todo, torna-se necessária a explanação das conhecidas influências de cada um deles em situações experimentais.

\section{Infiltração de neutrófilos (Papel do TGF- $\beta$, MCP-1, MIP2/GRO- $\alpha$, IL-6, IL-8, IP-10 e IL-10)}

A transmigração dos neutrófilos para tecidos lesados é um fenômeno precoce do processo de reparo. Ocorre quase que de imediato após sinalização dos neutrófilos retidos pelo coágulo, macrófagos residentes e células estromais. Citocinas (principalmente IL-1 e TNF- $\alpha$ ), atuando sobre os receptores das células endoteliais, induzem a produção de óxido nítrico (NO) bem como a expressão de moléculas de adesão para neutrófilos. A expressão das proteínas de adesão é, neste momento, o elemento mais importante para a migração de neutrófilos. Mesmo estando formado o gradiente químico de moléculas quimioatraentes, se estas não estiverem expressas na membrana das células endoteliais, a força de arraste da circulação não permite a adesão e transmigração leucocitária para o exterior do vaso.

Com relação às substâncias quimioatraentes para neutrófilos, o PDGF foi o primeiro fator de crescimento cuja propriedade quimiotática sobre macrófagos, neutrófilos e fibroblastos foi demonstrada (Heldin et al., 2002). Esta família de moléculas é formada por homo ou heterodímeros incluindo PDGF-AA, PDGF-AB, PDGFBB, PDGF-CC e PDGF-DD (Heldin et al., 2002). Imediatamente após a lesão, é liberado em grandes quantidades a partir da desgranulação das plaquetas (Breuing et al., 1997; Harris et al., 1995; Marikovsky et al., 1993; Matsuoka, Grotendorst, 1989; Ono et al., 1995; Soma et al., 1992; Trengove et al., 2000; Vogt et al., 1998) e a sua forma de expressão e de seus receptores sugerem uma forma parácrina de ação (Ashcroft et al., 1997; Beer et al., 2000, 1997). 
Moléculas da superfamília TGF- $\beta$, também, participam ativamente deste processo. Seus membros compreendem os TGF- $\beta$, TGF- $\beta$, e TGF- $\beta 3$ e ainda, BMP, inibinas e ativinas (Massagué, Pandiela, 1993). Em mamíferos, as três isoformas de TGF- $\beta$ (TGF- $\beta_{1}$, TGF- $\beta_{2}$ e TGF- $\beta_{3}$ ) são sintetizadas como precursores latentes, usualmente secretados como um complexo ligado à TGF- $\beta$ binding protein que extracelularmente sofre clivagem proteolítica (Roberts, 1998). De todos os membros desta família, o de importância para a infiltração de neutrófilos é o TGF- $\beta_{1}$ liberado das plaquetas em grandes quantidades imediatamente após a lesão (Assoian et al., 1983). O TGF- $\beta_{1}$ exerce função quimioatraente para neutrófilos, macrófagos e fibroblastos. Além disso, induz vários tipos celulares a produzir mais TGF- $\beta_{1}$ o que eleva sua concentração no foco inflamatório.

A família das quimiocinas (citocinas com atividade quimioatraentes sobre leucócitos) é composta de aproximadamente 50 membros que se subdividem em 4 famílias. Apesar da ação das quimiocinas ser mais evidente na quimiotaxia de macrófagos e linfócitos, alguns membros desta família de moléculas como a MCP-1 e o GRO$\alpha$ ou MIP-2 exercem esta função também sobre os neutrófilos (Christopherson \& Hromas, 2001). Em feridas de camundongos diabéticos $d b / d b$ tratadas com anticorpos neutralizantes para MCP-1 ocorre diminuição do número de neutrófilos e macrófagos, sugerindo o seu envolvimento direto na infiltração dessas células. O GRO- $\alpha$ e seu possível homólogo murino (MIP-2) são importantes reguladores da quimiotaxia de neutrófilos (Christopherson, Hromas, 2001). Em feridas por incisão, em humanos, o RNAm de GRO- $\alpha$ foi encontrado em altos níveis um dia após a lesão (Engelhard et al., 1998). Um outro membro da família das quimiocinas que participa na orientação de neutrófilos para o foco a lesão é a IL-8 (Rennekampff et al., 2000).

A IL-6 é considerada como um mediador fundamental em diversas etapas da inflamação (Gallucci et al., 2000). Dentre os vários efeitos pró-inflamatórios que lhe são atribuídos, os intimamente relacionados ao processo de reparo são, na etapa mais tardia, a indução mitótica de queratinócitos e, na fase mais precoce, os seus efeitos quimioatrativos sobre neutrófilos (Sato et al., 1999).

O processo de reparo tissular, de forma simplista, se faz pela indução de células lábeis (como exemplo, fibroblastos, células endoteliais e queratinócitos) para a mitose e da mudança de seus fenótipos de células fixas para migratórias. No caso dos fibroblastos, além dessas, também ocorre a mudança de fenótipo para células contráteis e secretórias dependendo da etapa. Para que a mitose e migração se realizem, é necessária a existência de um substrato sólido que sirva de base de sustentação para as células. A construção deste substrato é feita pela lise de constituintes inertes (exemplo, colágeno, integrinas, actina e fibronectina) da matriz extracelular seguida de sua reposição com características novas. Qualquer descontrole no processo lítico, ao invés de benefícios pode resultar em prejuízo à evolução para o reparo. Além disso, as células inflamatórias ativadas são produtoras de outras substâncias (como as espécies reativas de oxigênio e nitrogênio) com conhecido potencial lítico sobre as membranas celulares. Não bastassem essas duas formas de riscos potenciais à integridade tissular, alguns dos mediadores inflamatórios (como os TNFs e TGF- $\beta$ ) podem induzir apoptose das células via receptores de morte. Durante a evolução do reparo, alternam-se, de forma harmônica e sincronizada, momentos onde a lise predomina sobre a reposição celular e de matriz extracelular e vice-versa. O mesmo ocorrendo com a apoptose e indução mitótica. Existe, portanto, a necessidade de retroalimentação negativa ao processo. A IL-10 é um dos mais conhecidos sinalizadores negativos da inflamação. Acredita-se que ela seja o mais importante mediador com papel limitador e finalizador da resposta inflamatória. Adicionalmente, ela não só regula o crescimento ou diferenciação de várias células do sistema imune mas também de queratinócitos e células endoteliais (Moore et al., 2001). Picos na presença de seu RNAm foram encontrados por Ohshima (1998) 60 minutos após a lesão. Sato et al. (1999) encontraram dois picos de IL10 ao longo da evolução do reparo: o primeiro ocorreu três horas após a ferida e o segundo três dias após. Como principais fontes de RNAm de IL-10 foram indentificados os queratinócitos e o infiltrado mononuclear (Sato et al., 1999). O papel exato da presença do seu RNAm nos momentos iniciais da lesão e do segundo pico após três dias permanece por serem desvendados. No entanto, os efeitos conhecidos da IL-10 sobre os leucócitos sugerem a necessidade de modulação negativa da inflamação nestas etapas. Uma das suas formas de atuação se dá pela inibição da infiltração de neutrófilos e macrófagos aos sítios de injúria tissular (Sato et al., 1999).

\section{Infiltração de macrófagos \\ (Papel do TGF- $\beta$, MCP-1, MIP1- $\alpha$ e IL-10)}

Macrófagos derivados de monócitos começam a se acumular localmente entre o segundo e o quinto dias após a lesão, sendo suas funções primárias auxiliar os neutrófilos na fagocitose de microorganismos, debris teciduais, e remover neutrófilos senis. No entanto, a sua participação mais relevante na inflamação e reparo tissular é a produção e liberação local de diversos fatores de cres- 
cimento e citocinas, cruciais na maturação da reação inflamatória e na iniciação do processo de cura da ferida.

Após a fase inicial do processo inflamatório, a sinalização de moléculas do microambiente sobre as células endoteliais faz com que esta mude a expressão de moléculas da superfície voltada para o leito vascular de forma a facilitar a adesão de monócitos circulantes ao invés dos neutrófilos. Por processo semelhante ao dos neutrófilos, os monócitos, ao transmigrarem pelas fenestrações entre as células endoteliais, são ativados assumindo fenótipo de macrófagos derivados de monócitos. Uma vez fora do leito capilar, estas células são também conduzidas ao local da lesão orientada por um gradiente de mediadores químicos com ação quimioatraente. As moléculas da superfamília do TGF- $\beta$ (Assoian et al., 1983) e da família das PDGF (Heldin et al., 2002) são agentes quimiotáticos para neutrófilos e macrófagos. Já, na família das quimiocinas, somente o MCP-1 compartilha esta propriedade para as duas células (Christopherson, Hromas, 2001). Os membros desta última família que influenciam a migração de macrófagos são: o MIP1- $\alpha / C C L 3$ (DiPietro et al., 1998), RANTES (CCL5), MIP1- $\beta / C C L 4$, I309/CCL1, MCP-1 e MCP-3. IL-1, IL-6, IL-8 e o TNF- $\alpha$. Da mesma forma que para os neutrófilos, a IL-10 possui efeitos inibitórios sobre a quimiotaxia de macrófagos (Sato et al., 1999).

\section{Fibroplasia e deposição de matriz extracelular (Papel do TGF- $\beta$, ativina, MCP-1, PDGF, CTGF, CYR61, GM-CSF, FGF2, IGFs, IGF-1, NGF)}

Com a ativação de macrófagos na região lesada e a produção de fatores de crescimento específicos, a matriz extracelular começa a ser substituída por um tecido conjuntivo mais forte e mais elástico.

A fibroplasia tem início pela formação de tecido de granulação no espaço do ferimento, sendo formado por uma matriz frouxa de colágenos tipo I e II, fibronectina e ácido hialurônico contendo macrófagos, fibroblastos e vasos recém-formados e exudativos (Guidugli-Neto, 1992). Isto ocorre por volta do quarto dia após a lesão, onde são observados os novos fibroblastos acumulados misturando-se às neoformações de capilares (GuidugliNeto, 1987). Nessa etapa, a sinalização entre as células é feita por um número maior de mediadores e envolve, além da ativação das células para produção de mediadores, também a migração e indução de mitose das células estromais. Embora nessa etapa a formação de vasos já se encontre em curso e possua importante participação, os mediadores responsáveis pelo seu desencadeamento serão discutidos em separado a seguir.

Além das atividades quimioatraentes dos membros da superfamília do TGF- $\beta$, esses possuem também papel importante na fibroplasia. Está bem demonstrado que, in vitro, os TGF- $\beta_{1}$, TGF- $\beta_{2}$, TGF- $\beta_{3}$, são mitogênicos para fibroblastos, mas inibidores da proliferação de várias células incluindo os queratinócitos. Sua ação sobre os queratinócitos é paradoxal, uma vez que, de um lado exercem atividade antiproliferativa in vivo e in vitro (Coffey et al., 1988; Sellheyer et al., 1993) e de outro induz a expressão de integrinas necessárias para a sua migração pela matriz extracelular provisória rica em fibronectina (Gailit et al., 1994; Zambruno et al., 1995). Além disso, as três isoformas são potentes estimuladores da expressão de proteínas da matriz extracelular além das integrinas (Massagué, 1990, 1998; Roberts, Sporn, 1996). Além dos efeitos sobre a proliferação de fibroblastos, da sua ação sobre os queratinócitos e a deposição de matriz extracelular, os TGF- $\beta$ s participam também da diferenciação de miofibroblastos e do processo de angiogênese (Desmouliere et al., 1993; Roberts, Sporn, 1996; Roberts et al., 1986).

As ativinas são moléculas pertencentes à superfamília de TGF- $\beta$ que regulam vários aspectos do crescimento e diferenciação celulares em muitos órgãos e tecidos. Elas são encontradas como proteínas diméricas consistindo de duas subunidades $\beta_{A}$ (ativina $A$ ), duas subunidades $\beta_{B}$ (ativina $B$ ) ou subunidades $\beta_{A}$ e $\beta_{B}$ (ativina $A B$ ) (Massagué, 1990). A primeira evidência da participação das ativinas no processo de cicatrização, veio a partir dos estudos de Hübner et al. (1996). Eles demonstraram um aumento considerável na expressão de ativina $\mathrm{A}$ e aumento menor de ativina $\mathrm{B}$ e de seus respectivos receptores durante $\mathrm{o}$ processo de reparo de feridas do dorso de camundongos. Em estudos de hibridização in situ foi demonstrado que a expressão do RNAm de ativina $\beta_{\mathrm{A}}$ é predominante no tecido de granulação adjacente ao epitélio hiperproliferativo abaixo da crosta, enquanto altos níveis de RNAm de ativina $\mathrm{B}$, foram detectados na região suprabasal dos queratinócitos nas margens da lesão (Hübner et al., 1996). As ativinas inibem a proliferação de queratinócitos e, provavelmente, induzem em fibroblastos a expressão do EGF. Com isso, aumenta de forma considerável o tecido de granulação (Seishima et al., 1999; Shimizu et al., 1998). Atua também na estimulação da deposição de tecido de granulação porém de forma mais seletiva que os TGF- $\beta$ s. Enquanto estes últimos promovem uma deposição de maneira mais geral, as ativinas induzem de forma mais pronunciada a deposição de fibronectina e tenascina-C (Roberts et al., 1986).

Além das propriedades quimioatraentes do MCP-1 sobre monócitos/macrófagos, neutrófilos e células $\mathrm{T}$ (Baggiolini, 2001; Christopherson, Hromas, 2001), este 
também influencia a expressão de fatores de crescimento em macrófagos murinos (Low et al., 2001) e sua ação sobre fibroblastos induz a síntese de colágeno, aumenta a expressão de TGF- $\beta$ (Devalaraja et al., 2000) e da matriz de metaloproteinase-1 (DiPietro et al., 1998).

Está também comprovada a participação do PDGF nesta etapa do processo de reparo. Este fator contribui na estimulação de fibroblastos para a produção de matriz extracelular, estimula a sua proliferação e induz nestas células a sua mudança de fenótipo para miofibroblastos (Choi et al., 1996; Clark, 1993; Heldin, Westermark, 1999).

Membros da família CNN (CYR61/CTFG/NOV) possuem também participação na fibroplasia e deposição da matriz extracelular. Esta família é composta de 6 membros diferentes que são: (1) CTGF; (2) CYR61; (3)NOV; (4) WISP-1; (5) WISP-2; e (6) WISP-3. Estas proteínas são secretadas contendo 38 resíduos de cisteínas conservados e organizados estruturalmente de 4 maneiras distintas. Apesar de estarem mais envolvidas com o desenvolvimento e diferenciação embrionária, também estão presentes em alguns processos patológicos (Brigstock, 1999). O CTGF é expresso em muitos tecidos e órgãos e as primeiras evidências de sua participação no processo de reparo vieram a partir dos estudos de Igarashi et al. (1993). No processo de reparo, ele estimula diretamente a proliferação e quimiotaxia de fibroblastos (Bradham et al., 1991). É ainda um potente indutor da ligação das proteínas da matriz extracelular (como o colágeno tipo I e fibronectina) a seus receptores de integrina (Frazier et al., 1996), agindo, assim, como um modulador do TGF- $\beta_{1}$ neste processo (Kothapalli et al., 1997). Tem sido sugerido que o CTGF possui importante papel na patogênese dos processos fibróticos (Brigstock, 1999). O outro membro da família do CNN, a quem vem sendo atribuído papel no processo de reparo é a CYR61 que, também, é promotor da quimiotaxia de fibroblastos e aumenta o efeito mitogênico dos fatores de crescimento sobre estas células (Kireeva et al., 1996). Em outro estudo ficou demonstrado que a CYR61, além de regular a inflamação e a angiogênese, também regula a interação célula-matriz extracelular e o remodelamento da matriz após injúria da pele (Chen et al., 2001).

Além dos efeitos sobre a proliferação de granulócitos e macrófagos crescem evidências de que o GM-CSF possui papel importante no processo de reparo (Breuhahn et al., 2000; Mann et al., 2001). Em estudos realizados com camundongos transgênicos foi demonstrado que o GM-CSF leva a uma melhora substancial na neovascularização e formação do tecido de granulação que conseqüentemente acelera o processo de reepitelização. Ficou demonstrado nestes estudos, que este fator, além de afetar de forma di- reta sobre as células locais, atua também de forma indireta aumentando secundariamente o conteúdo de citocinas e de TGF-b1 na região da lesão (Mann et al., 2001).

A família dos FGF é composta de 22 membros estruturalmente relacionados (Ornitz, Itoh, 2001). Os FGFs possuem como característica a interação destes com heparina e proteoglicanos que os estabiliza da desnaturação térmica e proteolítica e limita a sua difusibilidade (Ornitz, 2000). Esta interação é ainda essencial para a sinalização de seus receptores (Ornitz, 2000). A maioria dos membros desta família possui um amplo espectro de ação mitogênica. Eles estimulam a proliferação de células de origem mesodermal, ectodermal e endodermal. Sobre esse aspecto, a única exceção é o KGF (FGF7) que parece ser específico para células epiteliais e de menor efeito em organismos adultos (Werner, 1998). Efeitos demonstrados in vivo são sugestivos do envolvimento destes fatores de crescimento com o processo de reparo, em particular os FGF1 e FGF2 (Babic et al., 1998). Os FGFs são mitogênicos para vários tipos celulares presentes no tecido lesado, incluindo fibroblastos e queratinócitos (Abraham, Klagsbrun, 1996). Dentre todos os FGFs, aqueles que vem demonstrando maior potencialidade de participação no processo de reparo são FGF1, FGF2, FGF4, FGF7 e o FGF10 (Abraham, Klagsbrun, 1996; Werner, 1998). Em lesão por queimadura em ratos, foi detectada imunoreatividade na regeneração da epiderme para o FGF2 que foi acompanhada de melhor regeneração desta, formação de tecido de granulação e renovação capilar (Kibe et al., 2000). Este fator foi também detectado nas margens de queimaduras em humanos (Gibran et al., 1994). Ademonstração da participação do FGF7 no processo de reparo foi feita por Guo et al. (1996). Posteriormente, foi verificado que seu RNAm era predominantemente detectado em fibroblastos da derme e em tecido de granulação de humanos e de camundongos (Marchese et al., 1995; Werner et al., 1992).

Os IGFs são potentes estimulantes da mitogênese e sobrevivência de muitos tipos celulares e exercem suas funções de forma autócrina, parácrina e endócrina (Clemmons, 1997; O’dell, Day, 1998). Seus efeitos são mediados pela ligação a receptores tirosina quinase que se assemelham aos receptores de insulina. Observa-se o efeito benéfico da administração exógena de IGF-I no reparo de tecidos, particularmente, quando associada a outros fatores de crescimento (Lynch et al., 1989). Há efetivamente expressão de IGF-I e IGF-II em ferimentos de diversas espécies (Marikovsky et al., 1996; Robertson et al., 1999; Steenfos, Jansson, 1992). Na pele normal, um número diminuto de células expressa receptores para IGFs. Porém, todas as células da epiderme e também 
macrófofagos e outras células inflamatórias passam a expressá-los entre 1e 3 dias após a lesão (Gartner et al., 1992; Jennische et al., 1987). O IGF-I aumenta a expressão da cadeia pró-alfa 1 (I) e da pró-alfa 1 (III) do procolágeno em cultura de fibroblastos da derme (Ghahary et al., 1995).

Está bem demonstrado que a inervação é essencial para a cicatrização de feridas (Harsum et al., 2001). O NGF é um polipeptídeo protótipo da família das neurotrofinas que são essenciais para o desenvolvimento e sobrevivência dos neurônios sensorais simpáticos no sistema nervoso central e periférico (Lewin, Mendell, 1993; Reynolds et al., 1997). Adicionalmente eles possuem funções importantes na iniciação e manuntenção da inflamação em vários órgãos, além, da sua ação sobre o crescimento de nervos. Está sendo agora sugerido que este fator participa também do processo de recuperação de lesões. Esta proposição está baseada no fato de que a remoção da glândula submandibular de camundongos retarda a contração de feridas da pele (Hutson et al., 1979) e, que, a lambida da pele aumenta esta contração. Uma vez que o NGV é encontrado em grandes concentrações na saliva, este efeito atribui-se a ele. Comprovou-se que a administração de NGF acelera a cicatrização de feridas em camundongos diabéticos (Li et al., 1980; Matsuda et $a l ., 1998)$ e a cicatrização de úlceras de pressão em humanos (Bernabei et al., 1999). O efeito do NGF sobre a cicatrização de feridas está basedo nos experimentos de Constantinou et al. (1994). Uma elevação na expressão de NGF foi encontrada em miofibroblastos do tecido de granulação de feridas de ratos (Hasan et al., 2000). Este também estimula a proliferação e inibe a apoptose de queratinócitos (Pincelli, 2000) e aumenta a proliferação e a expressão de moléculas de adesão de células endoteliais da microvasculatura (Raychaudhuri et al., 2001). É um potente estimulador da migração de fibroblastos, aumenta a expressão de $\alpha$-actina e a contração do gel de colágeno destas células (Micera et al., 2001).

\section{ANGIOGÊNESE \\ Papel do MCP-1, IL-8, CTGF, CYR61, GM-CFS, FGF2, VEGF-A, PLGF, HGF, Angiopoetinas, GRO-a e IP-10}

A maioria dos mediadores envolvidos na fibroplasia como MCP-1, IL-8, CTGF, CYR61, GM-CFS, FGFs e NGF também possuem atividade angiogênica. O papel do MCP-1 na angiogênese, dentre outros efeitos, foi demonstrado em estudos com camundongos knock-out para esta proteína por Low et al. (2001). Recentemente, foi demonstrado que CTGF promove, in vitro, a proliferação, migração e sobrevivência de células endoteliais e, que in vivo induz angiogênese (Babic et al., 1999; Hutson et al., 1979), juntamente com a CYR61 (Babic et al., 1998). O papel do GM-CFS sobre a migração e proliferação de células endoteliais foi estudado por Bussolino et al. (1989) e a demonstração de que FGF1 e FGF2 estimulam a angiogênese em vários modelos de ensaios foi descrita por Risau (1990).

Além das proteínas citadas acima, outros sinalizadores contribuem para a formação de novos vasos. O primeiro deles é o VEGF. Atualmente a família do VEGF inclui o VEGF-A, VEGF-B, VEGF-C, VEGF-D, VEGFE e o PLGF. O VEGF-A está sendo identificado como o principal regulador da vasculogênese e angiogênese durante o desenvolvimento (Gale, Yancopoulos, 1999). Os macrófagos e os queratinócitos da região em reparo aumentam de forma pronunciada a expressão gênica de VEGF-A (Brown et al., 1992; Frank et al., 1995) e seus receptores estão aumentados nos vasos sangüíneas do tecido de granulação (Lauer et al., 2000; Peters et al., 1993). A associação destes fatos, por si só, são indicativos fortes de sua participação na angiogênese. Esta hipótese foi recentemente reforçada pela demonstração de que a sua neutralização por anticorpos reduz a angiogênese, a formação de tecido de granulação e o acúmulo de fluidos em regiões que sofreram lesão (Howdieshell et al., 2001).

Outro membro da família do VEGF cuja participação na angiogênese vem assumindo importância é o PLGF. As células endoteliais dos capilares adjacentes à ferida expressam PLGF (Failla et al., 2000) e o aumento da sua expressão parece ter importância funcional. Em camundongos knock-out para esta proteína, a angiogênese é defeituosa (Carmeliet et al., 2000) e no mesmo estudo foi detectado um sinergismo entre VEGF-A e PLGF.

A expressão do HGF e de seu receptor ocorre em queratinócitos de lesões da epiderme, e, também, em vários outros tipos de células dos tecidos de granulação durante a cicatrização em ratos (Cowin et al., 2001). A provável importância funcional do aumento de expressão de HGF é a regulação de uma proteína denominada metalotioneína (zinco), cuja principal função é a proteção celular contra o estresse oxidativo desencadeado pela presença de metais pesados (tais como cádmio e mercúrio) e responsável pelo controle do conteúdo de zinco nos tecidos. Camundongos transgênicos com superexpressão de HGF apresenta aumento do tecido de granulação que é acompanhado de elevação do número de vasos no local de incisões cirúrgicas. O aumento do número de vasos é, também, parcialmente mediado pelo VEGF-A, uma vez que, mais tardiamente ocorre aumento de sua expressão (Cowin et al., 2001). Ao contrário, a reepitelização não é afetada pelo aumento da expressão de HGF (Cowin et al., 2001). 
As moléculas da família das quimiocinas com influência sobre a angiogênese são o GRO- $\alpha$ e o IP-10. A primeira possui ação indutora e a segunda inibidora. Altas concentrações de GRO- $\alpha$ são encontradas na fase inicial da inflamação onde além da ação quimioatraente apresenta ainda papel na migração de queratinócitos e na neovascularização (Engelhardt et al., 1998). Já o IP-10/ CXCL10, é inicialmente detectado em altos níveis em várias condições inflamatórias crônicas como a psoríase. Os membros desta família atuam primariamente no recrutamento de linfócitos via receptor CXCR3. Está demonstrado que o aumento da sua expressão ocorre juntamente com o da monocina induzida pelo IFN-gama (CXCL9) no ferimento (Engelhardt et al., 1998). Para determinar o efeito da IP-10/CXCL10 na resposta inflamatória in vivo, Luster et al. (1988) projetaram um camundongo que constitutivamente a expressava em queratinócitos. Após lesão, estes camundongos apresentaram uma fase inflamatória mais intensa que o controle, retardamento na reepitelização e fase de granulação desorganizada ficando, ao final, demonstrado o seu efeito inibitório sobre a angiogênese (Belperio et al., 2000). Assim, o IP/CXCL possivelmente inibe o reparo de feridas pela sua interferência no desenvolvimento da granulação em tecidos normais. Este efeito pode ser parcialmente resultante de uma ação inibitória sobre a motilidade de fibrobalastos após ativação por EGF (Shiraha et al., 1999).

Mais recentemente, Strieter et al. (1995) demonstraram que outras quimiocinas $\mathrm{CXC}$, além do GRO- $\alpha$, possuem papel na angiogênese. Eles observaram que as quimiocinas que contém sítios Glu-Leu-Arg (ELR) adjacente ao seu primeiro aminoácido cisteína na região $\mathrm{NH}_{2}$ terminal são potentes promotores de angiogênese. As quimiocinas que possuem o sítio ELR além do GRO- $\alpha$, são o GRO- $\beta$ (CXCL2), o GRO- $\gamma$ (CXCL3), CTAP-III, $\beta$ tromboglobulina e o NAP-2 (Strieter et al. 1995; Belperio et al., 2000).

\section{CICATRIZAÇÃO (Papel de IGF-1, TGF- $\beta$, Ativina, CTGF, IL-6, IL-10)}

A fase final da cura de uma ferida é a maturação e remodelagem da matriz extracelular. É durante essa fase que a cicatriz adquire sua máxima resistência tênsil. A característica mais marcante desta fase do reparo é a grande e acelerada deposição de colágeno na região da ferida. Assim, os sinalizadores de importância, de alguma forma, devem exercer influência sobre os fibroblastos ou sobre as células produtoras de sinalizadores que influenciam estas. Um desses sinalizadores é o IGF-I e seu efeito conhecido no aumento da expressão da cadeia pró-alfa
1 (I) e da pró-alfa 1 (III) do procolágeno em cultura de fibroblastos da derme (Ghahary et al., 1995). Outro indicativo importante de sua participação nesta fase do reparo é que, em parte, as feridas de pacientes diabéticos, tornam-se crônicas devido à sua sua ausência nos queratinócitos e fibroblastos da camada basal da epiderme (Blakytny et al., 2000). Além disso, tem sido atribuída à sua superexpressão, a formação de cicatriz hipertrófica após queimaduras (Gahary et al., 1995).

O TGF- $\beta$ é outro sinalizador com participação importante nessa fase. Ele é um mitógeno importante de fibroblastos. Embora exercendo efeitos inibitórios sobre a proliferação dos queratinócitos, é um potente estimulador da expressão de proteínas da matriz extracelular e de integrinas (Massagué, 1990, 1998; Roberts, Sporn, 1996). Shah et al. (1994), em experimentos com feridas tratadas com anticorpos neutralizantes de TGF- $\beta_{1}$ ou combinações de TGF- $\beta_{1}$ e TGF- $\beta_{2}$, observaram que este tratamento leva a uma redução significativa na deposição de matriz extracelular e à subseqüente cicatrização (Shah et al., 1994, 1995). Uma redução na cicatrização foi também observada em feridas de camundongos tratadas topicamente com oligonucleotídeos antisense de TGF- $\beta_{1}$ (Choi et al., 1996). Também o uso de antagonistas sintéticos de TGF- $\beta_{1}$ reduz a cicatrização de queimaduras em porcos e a cicatriz incisional em coelhos (Huang et al., 2002). Estudos envolvendo a isoforma TGF- $\beta_{3}$ apresentam resultados contraditórios. Apesar de Cox (1995) ter demonstrado aumento na deposição de nova matriz pela aplicação de TGF- $\beta_{3}$ exógena (Cribbs et al., 2002), Ring et al. (2000) verificaram que a aplicação de TGF- $\beta_{3}$ recombinante inibe a cicatrização indicando que este tipo de TGF- $\beta$ antagoniza os efeitos das outras duas isoformas (Shah et al., 1995).

A expressão de ativina $\beta_{\mathrm{A}}$ e em menor concentração da ativina $\beta_{\mathrm{B}}$ aumenta de forma considerável vinte e quatro horas após a lesão e permanece em concentrações elevadas até o final do processo de reparo (Hübner et al., 1996; Wankell et al., 2001). Apesar de inibirem a proliferação de queratinócitos, induzem em fibroblastos a expressão do EGF e com isto aumentam de forma considerável o tecido de granulação (Seishima et al., 1999; Shimizu et al., 1998). Enquanto os TGF- $\beta$ s promovem deposição de tecido de granulação e de matriz extracelular de forma geral, as ativinas induzem de forma mais pronunciada a deposição de fibronectina e tenascina-C (Roberts et al., 1986). Em animais transgênicos para a superexpressão de ativina $\beta_{\mathrm{A}}$ a cicatrização apresenta-se com espessamento epidermal e fibrose de derme (Munz et al., 1999). Por outro lado, a pele de camundongos transgênicos com superexpressão de folistatina (antagonista da ativina $\beta_{\mathrm{A}}$ ) 
apresenta uma tênue camada de derme e uma subepiderme atrofiada. Após lesão, um atraso severo do processo cicatricional é observado. Estes resultados são indicativos do envolvimento das ativinas no evento de cicatrização (Munz et al., 1999).

O RNAm do CTGF foi encontrado após um dia de lesão por Kothapalli et al., (1997) e nove dias após a lesão por Igarashi et al. (1993). Este mediador, além de possuir propriedades quimiotáticas sobre os fibroblastos (Bradham et al., 1991), modula o conteúdo de TGF- $\beta_{1}$ nas regiões das feridas (Kothapalli et al., 1997). Mais recentemente foram demonstrados seus efeitos sobre a proliferação, migração, sobrevivência e adesão in vitro de células endoteliais (Babic et al., 1999; Shimo et al., 1999), o que sugere a sua participação, também, na angiogênese. Devido às características descritas e a sua detecção em várias etapas do reparo, é provável que este fator de crescimento seja fundamental também na formação do tecido cicatricial.

Os efeitos antiinflamatórios da IL-10 discutidos acima e seu efeito regulador sobre o crescimento e diferenciação de várias células do sistema imune, queratinócitos e células endoteliais (Moore et al., 2001) indicam que a sua participação no reparo não se restringe à regulação negativa da inflamação. Sendo os queratinócitos e o infiltrado mononuclear as principais fontes de RNAm de IL-10 (Sato et al., 1999), é possível que este exerça funções mais diretas também sobre a cicatrização e reepitelização. A identificação de um pico de RNAm de IL-10 nos momentos iniciais da lesão e (principalmente) de um segundo pico após três dias são fortes indicativos desta participação.

\section{REEPITELIZAÇÃO}

\section{(Participação do aumento de FGF2, FGF7, FGF10, EGF, TGF- $\alpha$, HB-EGF, NDF, IGFs, NGF, Ativina, MCP-1, IL-6, GM-CSF, Leptina, GRO- $\alpha$, e da redução de TGF- $\beta$, BMP-6, IP-10)}

Com relação à modelagem da matriz extracelular, quimiocinas como IL-8, RANTES, MIP- $1 \alpha$, MIP- $1 \beta$ e MCP-1, além de suas ações quimioatraentes sobre neutrófilos e macrófagos derivados de monócitos, induzem a expressão de metaloproteinases em vários tipos de leucócitos (DiPietro et al., 1995, 2001; D’Souza et al., 2001). Exemplos de mediadores relacionados à angiogênese e com influência direta sobre as células de revestimento são o VEGF-A e o PLGF. A expressão desses apresentam-se também aumentada durante a migração de queratinócitos (Failla et al., 2000). Outros dois mediadores que participam da reconstrução epitelial além de suas ações angiogênicas são o HGF e o GRO- $\alpha$. O HGF foi inicialmente descoberto como um poderoso mitógeno de hepatócitos. Na região da ferida, este fator auxilia na recomposição celular e estimula a dissociação das células epiteliais (Comoglio \& Boccaccio, 2001). Em experimentos in vitro, o GRO- $\alpha$ apresenta intensa atividade mitogênica para queratinócitos, sugerindo o seu envolvimento na reepitelização. Porém, acompanhando este efeito do GRO- $\alpha$, foi observada redução significativa na contração da ferida (Rennekampff et al., 1997). O efeito do TGF- $\beta_{1}$ na reepitelização é aparentemente paradoxal. De um lado, tanto in vivo como in vitro inibe a proliferação de queratinócitos, o que sugere ser este um regulador negativo da reepetilização e de outro induz a expressão da integrina que é fundamental para a migração destas células sobre a matriz provisória rica em fibronectina (Gailit et al., 1994; Zambruno et al., 1995).

Outros membros da família do TGF- $\beta$ com participação na reepitelização são as ativinas e as BMPs. A cicatriz de camundongos transgênicos que superexpressam a ativina $\beta \mathrm{A}$ é caracterizada por espessamento epidermal e derme fibrótica. Como possível causa do espessamento epidermal, foi observado aumento de duas a três vezes na taxa de proliferação de queratinócitos epidermais. Este efeito da ativina sobre a proliferação de queratinócitos pode ser indireto uma vez que esta inibe a proliferação de queratinócitos humanos (Seishima et al., 1999; Shimizu et al., 1998). A ativina pode estimular os fibroblastos para a expressão de fatores de crescimento, que paracrinamente estimula a proliferação dos queratinócitos. O papel das BMPs na reepitelização é contrário ao da ativina. Após o fechamento da ferida, a BMP-6 acumula-se por toda a camada suprabasal da nova epiderme formada (Kaiser et al., 1998). Esta localização sugere sua participação na diferenciação de queratinócitos que os leva a cessarem sua atividade mitótica. Esta suposição é reforçada pelo fato de que a BMP-6 induz diferenciação de queratinócitos in vitro (D'Souza et al., 2001; McDonnell et al., 2001) e, também, devido aos camundongos que a superexpressam apresentarem um atraso no processo de reepitelização (Kaiser et al., 1998). A inibição da proliferação de queratinócitos parece ser necessária para o restabelecimento e total diferenciação da epiderme.

Efeito semelhante ao da BMP-6 tem sido também atribuído ao TNF. Para avaliar seu papel no reparo, Mori et al. (2002) utilizaram camundongos deficientes de seu receptor. As feridas destes animais demonstraram aumento da angiogênese, reepitelização e do conteúdo de colágeno. As diferenças histológicas foram acompanhadas de aumento na expressão de TGF- $\beta_{1}$, CTGF, VEGF, VEGFR-1 e VGFR-2. Como a ausência do receptor de TNF em camundongos facilita a evolução da angiogênese 
e reepitelização, é provável que em situações normais este exerce papel contrário, ou seja, possui ações inibitórias sobre estes processos.

A diminuição de IGF é responsável, pelo menos em parte, pela patogênese de feridas crônicas em pacientes diabéticos. Isto pode estar relacionado as suas ações sobre os queratinócitos e fibroblastos. Esta proteína está ausente na camada basal da epiderme de diabéticos e em seus fibroblastos. Mais recentemente foi demonstrado que o IGF está também ausente nos queratinócitos das bordas de úlceras de pé de diabéticos (Blakytny et al., 2000). Isso dificulta a reepitelização deste tipo de lesão além de comprometer já a deposição de matriz extracelular. Outro mediador que pode ter particular importância na reepitelização de feridas em diabéticos é o NGF. A administração de NGF exerce efeito protetor contra neuropatia sensorial (Apfel et al., 1994) e nos queratinócitos de diabéticos este fator está depletado (Anand et al., 1996). Como o NGF é um estimulador da proliferação de queratinócitos e inibidor de sua apoptose in vitro (Pincelli, 2000), a sua importância para estes pacientes se dá de forma indireta restabelecendo funções sensoriais e de forma direta agindo sobre os queratinócitos.

As ações da IL-6 no processo de reparo não se restringem à seu efeito quimioatraente sobre os neutrófilos na fase inflamatória. A diversidade de células no foco da lesão que expressam IL-6 e seu receptor somada a sua presença ao longo de toda a evolução da inflamação sugerem uma participação mais proeminente desta citocina no reparo. Sato et al. (1999) demonstraram que a IL-6 exerce efeitos mitogênicos sobre os queratinócitos e Gallucci et al. (2000) demonstraram que em camundongos knockout para IL-6 o processo de reparo evolui lentamente. Nestes experimentos, a administração tópica de IL-6 exógena reverte o processo e restabelece a reepitelização.

O GM-CSF possui ação mitogênica sobre queratinócitos (Kawada et al., 1997; Groves, Schmidt-Lucke, 2000) e também estimula a migração e proliferação de células endoteliais (Bussolino et al., 1989). Camundongos que superexpressam GM-CSF na epiderme (Breuhahn et al., 2000) apresentam reepitelização acelerada resultante de aumento da proliferação de queratinócitos (Mann et al., 2001). A concentração elevada de outras citocinas importantes para o reparo das lesões destes animais demonstra que o GM-CSF age de maneira direta e indireta pela indução da produção secundária de outras citocinas (Mann et al., 2001).

A leptina é um hormônio secretado pelos adipócitos e produto do gene $o b$. Possui influência na redução da ingestão alimentar e no aumento do gasto energético pela sua ação no hipotalámo (Ceddia et al., 1998). Além dos adipócitos, a leptina é produzida também na placenta, estômago e glândula mamária, bem como no coração e cartilagem óssea. Apesar da produção em vários tecidos os valores de leptina circulantes estão mais estreitamente relacionados com a gordura corporal. Inúmeros fatores influenciam a produção de leptina incluindo a alimentação, insulina, glicocorticóides e testosterona. A administração sistêmica e tópica de leptina acelera a reepitelização (Frank et al., 2000) sem influenciar a angiogênese (Ring et al., 2000; Stallmeyer et al., 2001). A comprovação de que estes efeitos são mediados via receptor de leptina veio da ineficiência na reepitelização de feridas de camundongos diabéticos $d b / d b$ geneticamente deficientes do seu receptor (Blessing et al., 1996; Ring et al., 2000).

Como discutido acima, a maioria dos membros da família dos FGFs possui um amplo espectro de ação mitogênica. Estes estimulam a proliferação de células de origem mesodermal, ectodermal e endodermal e também de vários tipos celulares presentes no tecido lesado, incluindo fibroblastos e queratinócitos (Abraham, Klagsbrun, 1996). O FGF7 parece ser o único membro dessa família específico para células epiteliais e de menor potência em organismos adultos (Werner, 1998). O seu receptor de alta afinidade (FGFR2IIIb) é superexpresso em queratinócitos de feridas de humanos e porcos (Danilenko et al., 1995; Marchese et al., 1995). O FGF2 foi encontrado em queratinócitos basais na epiderme de feridas hiperproliferativa e normal (Kurita et al., 1992). Antoniades et al. (1993) encontraram uma regulação positiva de FGF1 e FGF2 em queratinócitos da epiderme de feridas de porcos. Estes resultados são demonstrativos de que os membros da família dos fatores de crescimento derivados de fibroblastos participam em várias etapas do processo de reparo e possuem papel importante também na reepitelização.

A família do EGF compreende as moléculas cujos efeitos sobre a reepitelização são mais estudados e característicos. Esta família é composta, além do próprio EGF, também pelo TGF- $\alpha$, HB-EGF, amphiregulin, epiregulin, betacellulin, o recentemente descoberto epigen, e as proteínas codificadas pelo vírus Vaccinia e outras poxviroses (Strachan et al., 2001; Tzahar et al., 1998; Yarden, 2001). Além das neuroregulins outras proteínas mais distantemente a ela relacionadas como as heregulins e NDF podem também se ligar a alguns receptores de EGF. Esses fatores de crescimento exercem suas funções ligando-se aos receptores de alta afinidade: EGFR/ErbB1, HER2/ErbB2, HER3/ErbB3 ou HER4/ErbB4.

A primeira evidência de que o receptor de EGF influencia o reparo foi obtida por Grotendorst et al. (1989). A partir dele uma série de estudos clínicos e experimentais demonstram efeito positivo do EGF, TGF- $\alpha$ e HB-EGF no 
reparo de feridas, sugerindo que endogenamente estes fatores estão envolvidos com o processo de cura das feridas (Greenhalgh, 1996; Schultz et al., 1987; Steed, 1998). O efeito do HB-EGF sobre a proliferação de fibroblastos e queratinócitos foi demonstrado por Marikovsky (1993). Além desta ação, este autor demonstrou um sinergismo entre o HB-EGF e o IGF I na proliferação de queratinócitos in vitro (Marikovsky et al., 1996). Rappolee et al. (1988) detectaram a presença de RNAm do TGF-a em macrófagos isolados de feridas (Rappolle et al., 1988). Em modelo de hibridização in situ, este fator de crescimento foi detectado por imuno-histoquímica em eosinófilos de feridas de coelhos e de hamsters (Todd et al., 1991; Wong et al., 1993). O TGF- $\alpha$ foi também encontrado em queimaduras de ratos, principalmente durante a fase de proliferação de queratinócitos (Cribbs et al., 2002). Estes resultados são demonstrativos da participação deste fator de crescimento durante a reepitelização de lesões cutâneas.

\section{CONCLUSÃO}

O reparo tissular é um processo complexo, que envolve a interação entre células estromais e circulatórias que são ativadas por uma plêiade de mediadores de natureza química diversificada, fragmentos de células e matriz extracelular, microorganismos e por alterações físico-químicas no microambiente da lesão e das áreas a ela circunjacentes. A ativação dessas células as leva a profundas alterações na sua expressão gênica e modificam drasticamente as suas características fenotípicas. A produção e presença de mediadores protéicos e lipídicos são críticos para o processo, uma vez que a migração celular, a indução mitótica de células lábeis locais e a produção de matriz extracelular são eventos centrais. Na sua evolução, alternam-se harmoniosamente momentos de predomínio de reações catabólicas sobre anabólicas e vice-versa. Embora didaticamente o processo esteja divido em três fases, na realidade elas não são estanques e sim interdependentes e sobrepostas dinamicamente no tempo. Para a evolução de cada uma das fases, ocorrem eventos celulares (como migração e transmigração celular), tissulares (como vasoconstrição, vasodilatação, angiogênese e formação de tecido de granulação) e metabólicos (como coagulação e deposição de matriz extracelular). Estes eventos também são interdependentes e possuem uma cronologia prédefinida. Dependendo da etapa, determinadas células e mediadores possuem relevância mais destacada. Assim, os aspectos centrais aqui abordados devem ser os balizadores das condutas terapêuticas a serem adotadas quando a intervenção sobre o processo for necessária. Para a otimização da intervenção, torna-se necessário conheci- mento prévio da cronologia da lesão, a fim de presumir a etapa e os prováveis eventos de ocorrência naquele dado momento. A partir dessa análise deve ser eleita qual forma de intervenção teria a maior probabilidade de potencializar o evento predominante. Ou seja, de nada adiantaria a administração de potencializadores da migração de neutrófilos, se a análise cronológica da lesão indicar que o momento é de predomínio da reepitelização. Da mesma forma, a administração de estimuladores da migração de queratinócitos não teria efeito nos momentos iniciais da lesão.

Nos casos de lesões crônicas, os critérios de avaliação são mais complexos. Além da identificação do elemento causal da cronificação, é necessário identificar qual dos eventos do processo de reparo mais ressente o seu impacto. Após a remoção do agente causal, os critérios devem seguir a mesma orientação anterior. Na impossibilidade de remoção do agente causal, as atenções devem ser dirigidas para potencializar o evento (ou eventos) que ele está negativamente influenciando.

\section{LISTA DE ABREVIATURAS}

ADP - Adenosine Diphosphate

BMP - Bone morphogenetic proteins

CCL 1,4,5-CC ligand 1,4,5

CTAP III - Chemokine-connective tissue-activating peptide III

CTGF - Connective Tissue Growth Factor

CXCL 9-CXC Chemokine ligand 9

CXCR 1,2,3 - CXC Chemokine receptor 1, 2, 3

CYR61 - Cysteine-rich 61

EGF - Epidermal Growth Factor

ENA-78 - Neutophil-Activating Peptide 78

FGF - Fibroblast Growth Factor

GM-CSF - Granulocyte Macrophage Colony

Stimulating Factor

GROa - Growth-related oncogene a

HB-EGF - Heparin-binding epidermal growth factor HER (ErbB) - Human Epidermal growth factor Receptor

HGF - Hepatocyte Growth Factor

IFN-gamma - Interferon-gama

IGF - Insulin-like Growth Factor

IL-1,6,8,10 - Interleukin 1,6,8,10

IP10 - Interferon-inducible protein 10

KGF - Keratinocyte Growth Factor

MCP 1 - Monocyte Chemoattractant Protein 1

MIP 2 - Macrophage Inflammatory Protein 2

NAP 2-Neutrophil-activating peptide 2

NDF - Neu differentiation factors 
NGF - Nerve Growth Factor

NOV - Nefroblastoma overexpressed

PAF - Platelet Activating Factor

PDGF - Platelet-Derived Growth Factor

PLGF - Placenta Growth Factor

RANTES - Regulated upon activation of normal T cell expressed and secreted

TGF- $\beta$ - Transforming Growth Factor $\beta$

TNF- $\alpha$ - Tumor Necrosis Factor $\alpha$

$\mathrm{TxA}_{2}$ - Tromboxane $\mathrm{A}_{2}$ VEGF - Vascular Endothelial Growth Factor

WISP - Wnt-Induced secreted protein

\section{ABSTRACT \\ Mechanisms involved in wound healing: a revision}

The mechanisms involved in tissue repair are revised. The wound healing process occurs basically in three phases: inflammation, formation of granulating tissue and extracellular tissue deposition, and tissue remodeling. The cellular and tissue events of each phase are described and discussed. The chemical mediators and their interplay with the wound healing events and cells involved are also discussed. However, especial attention was given to the role played by the growth factors in the tissue repair process.

Uniterms: Wound healing. Leukocytes. Fibroblasts. Keratinocytes. Platelets. Growth factors. Cytokines.

\section{REFERÊNCIAS BIBLIOGRÁFICAS}

ABRAHAM, J.A.; KLAGSBRUN, M. Modulation of wound repair by members of the fibroblast growth factor family. In: The Molecular and Cellular Biology of Wound Repair. 2. ed. New York: Plenum, 1996. p.195-248.

AMBROSE, J. Á; WEINRAUCH, M. Thrombosis in ischemic heart disease. Arch. Intern. Med., v. 156, p. 1382-1394, 1996.

AMOS, D. J.; Tonkin, A.M.; White, H.D. New insights into the patogenesis, prevention and management of acute coronary sindromys. Aust. N.Z. J. Med., v. 26, p. 344-348, 1996.
ANAND, P.; TERENGHI, G.; WARNER, G.; KOPELMAN, P.; WILLIAMS-CHESTNUT, R.E.; SINICROPI, D.V. The role of endogenous nerve growth factor in human diabetic neuropathy. Nat. Med., v. 6, p. 703-707, 1996.

ANTONIADES, H.N.; GALANOPOUOLOS, T.; NEVILLE-GOLDEN KIRITSY, C.P.; LYNCH, S.E. Expression of growth factor and receptor mRNAs in skin epithelial cells following acute cutaneous injury. Am. J. Pathol., v. 142, p. 1099-1110, 1993.

APFEL, S.C.; AREZZO, J.C.; BROWNLEE, M.; FEDEROFF, H.; KESSLER, J.A. Nerve growth factor administration protects against experimental diabetic sensory neuropathy. Brain. Res., v. 634, p. 7-12, 1994.

ASHCROFT, G.S.; HORAN, M.A.; FERGUNSON, N.W. The effects of ageing on wound healing: immunolocalisation of growth factors and their receptors in a murine incisional model. J. Anot., v. 190, p. 351-365, 1997.

ASSOSIAN, R.K.; KOMORIYA, A.; MEYERS, C.A.; MILLER, D.M.; SPORN, M.B. Transforming growth factor-beta in human platelets. Identification of a major storage site, purification, and characterization. J. Biol. Chem., v. 158, p. 7155-7160, 1983.

BABIC, A.M.; CHEN, C.C.; LAU, L.F. Fisp 12/mouse connective tissue growth factor mediates endothelial cells adhesion and migration through integrin alphavbeta3, promotes endothelial cell survival, and induces angiogenesis in vivo. Mol. Cell. Biol., v. 19, p. 29582966, 1999.

BABIC, A.M.; KIREEVA, M.L.; KOLESNIKIVA, T.V.; LAU, L.F. Cyr61, a product of a growth factor-inducible immediate early gene, promotes angiogenesis and tumor growth. Proc. Natl. Acad. Sci. USA, v. 95, p. 6355-6360, 1998.

BAGGIOLINI, M. Chemokines in pathology and medicine. J. Intern. Med., v. 250, p. 91-104, 2001.

BEER, H.D.; FASSLER, R.; WERNER, S. glucocorticoidregulated gene expression during cutaneous wound repair. Vitam. Horm., v. 59, p. 217-239, 2000. 
BEER, H.D.; LONGAKER, M.T.; WERNER, S. reduced expression of PDGF and PDGF receptors during impaired wound healing. J. Invest. Dermatol., v. 109, p. 132-138, 1997.

BELPERIO, J. A.; KEANE, M. P.; ARENBERG, D. A.; ADDISON, C. L.; EHLERT, J. E.; BURDICK, M. D.; STRIETER, R. M. CXC chemokines in angiogenesis. $J$. Leukoc. Biol., v. 68, p. 1-8, 2000.

BERNABEI, R.; LANDI, F.; BONINI, S.; ONDER, G.; LAMBIASE, A. POLA, R. ALOE, L. Effect of topical application of nerve growth-factor on pressure ulcers. Lancet, v. 354, p. 307, 1999.

BLAKYTNY, R.; JUDE, E.B.; MARTIN GIBSON, J.; BOULTON, A.J.; FERGUSON, M.W. Lack of insulinlike growth factor 1 (IGF1) in the basal keratinocyte layer of diabetic skin and diabetic foot ulcers. J. Pathol., v. 190, p. 589-594, 2000.

BLESSING, M.; SCHIRMACHER, P.; KAISER, S. Overexpression of bone morphogenetic protein-6 (BMP6) in the epidermis of transgenic mice: inhibition or stimulation of proliferation depending on the pattern of transgene expression and formation of psoriatic lesions. J. Cell. Biol., v. 135, p. 227-239, 1996.

BLOTNIK, S.; PEOPLES, G. E.; FREEMAN, M. R. E.; EBERLEIN, T. J.; KLAGSBRUN, M. T lymphocytes synthesize and export heparing-binding epidermal growth factor-like growth factor and basic fibroblast growth factor, mitogens for vascular cells and fibroblast differential production and release by $\mathrm{CD}^{+}$and $\mathrm{CD} 8^{+} \mathrm{T}$ cells. Proc. Natl. Acad. SCI. USA., v. 91, p. 2890-2894, 1994.

BRADHAM, D.M.; IGARASHI, A.; POTTER, L.R.; GROTENDORST, G.R. Conective tissue growth factor: a cysteine-rich mitogen secreted by human vacular endothelial cells is related to the SRC-induced immediate early gene product CEF-10. J. Cell. Biol., v. 114, p. 12851294, 1991.

BRANDT, E.; PETERSON, F.; LUDWIG, A.; EHLERT, J. E.; BOCK, L., Fald, H. D. The beta-thhromboglobulins and platelelt factor 4: blood platelet derived CXC chemokines with divergent roles in early neutrophil regulation. J. Leukoc. Biol., v. 67, p. 471-478, 2000.
BREUHAHN, K.; MANN, A.; MULLER, G.; WILHELMI, A.; A; SCHIRMARCHER, P.; ENK, A.; BLESSING, M. epidermal overexpression of granulocyte-macrophage colony-stimulating factor induces both keratinocyte proliferation and apoptosis. Cell Growth Differ., v. 11, p. 111-121, 2000.

BREUING, K., ANDREE, C.; HELO, G.; SLAMA, J.; LIY, P.Y.; ERIKSSON, E. Growth factors in the repair of partial thickness porcine skin wounds. Plast. Reconstr. Surg., v. 100, p. 657-664, 1997.

BRIGSTOCK, D.R. The conective tissue growth factor/ cysteine-rich 61/nephroblastoma overescpressed (CCN) family. Endocr. Ver., v. 20, p. 189-206, 1999.

BROWN, L.F.; YEO, K.T.; BERSE, B.; YEO, T.K.; SENGER, D.R.; DVORAK, H.F.; VAN DE WATER, L. Expression of vascular permeability factor (vascular endothelial growth factor) by epidermal keratinocytes during wound healing. J. Exp. Med., v. 176, p. 1375-1379, 1992.

BUSSOLINO, F.; WANG, J.M.; DEFILIPPI, P.; TURRINI, F.; SANAVIO, F.; EDGELL, C.J.; AGLETTA, M.; ARESE, P.; MANTOVANI, A. Granulocyte and granulocyte-macrophage-colony stimulating factors induce human endothelial cells to migrate and proliferate. Nature, v. 337, p. 461-463, 1989.

CARMELIET, P.; MOONS, L.; LUTTUN, A.; VINCENTI, V.; COMPERNOLLE, V.; DE MOL, M.; WU, Y.; BONO, F.; DEVY, L.; BECK, H.; SCHOLZ, D.; ACKER, T.; DIPALMA, T.; DEWERCHIN, M.; NOEL, A.; STALMANS, I.; BARRA, A.; BLACHER, S.; VENDENDRIESSCHE, T.; PONTEN, A.; ERIKSSON, U.; PLATE, K.H.; FOIDART, J.M.; SCHAPER, W.; CHARNOCK-JONES, S.; HICKLIN, D.J.; BERBERT, J.M.; COLLEN, D.; PERSICO, M.G. Synergism between vascular endothelial growth factors and placental growth factor contributes to angiogênesis and plasma extravasation in pathological conditions. Nature Med., v. 7, p. 575-583, 2001.

CEDDIA, R.B.; WILLIAM, W.N. JR.; LIMA, F.B.; CARPINELLI, A.R.; CURI, R. Pivotal role of leptin in insulin effects. Braz. J. Med. Biol. Res., v 31, p. 715-722, 1998. 
CHEN, C.C.; MO, F.E.; LAU, L.F. The angiogenic factor Cyr61 activates a genetic program for wound healing in human skin fibroblasts. J. Biol. Chem., v. 276, p. 4732946337, 2001.

CHOI, B.M.; KWAK, H.J.; JUN, C.D.; PARK, S.D.; KIM, K.Y.; KIM, H.R.; CHUNG, H.T. Control of scarring in adult wounds using antisense transforming growth factorbeta 1oligodeoxynucleotides. Immunol. Cell. Biol., v. 74, p. 144-150, 1996.

CHRISTOPHERSON, K.; HROMAS, R. Chemokine regulation of normal and pathologic immune responses. Stem Cells., v. 19, p. 388-396, 2001.

CLARK, R. A. F. Cutaneous tissue repair: basic biologic considerations I. Journal of the American Academy of Dermatology, v. 13, p. 701-725, 1985.

CLARK, R.A.; Regulation of fibroplasia in cutaneous wound repair. Am. J. Med. Sci., v. 306, p. 42-48, 1993.

CLARK. R. A. F. Biology of dermal wound repair dermatological clinics. Invest. Dermatol.. v. 11, p. 647$661,1993$.

CLEMMONS, D.R. Insulin-like growth factor binding proteins and their role in controlling IGF actions. Cytokine Growth Factor Rev., v. 8, p. 45-62, 1997.

COELHO O. R; ALMEIDA A; CIRILLO W; UETI O. M. Y. Glicoproteína IIb/IIIa em isquemia miocárdica. Soc. Cardiol. Estado de São Paulo, v. 8, p. 338-343, 1998.

COFFEY, R.J. Jr.; BASCOM, C.C.; SIPES, N.J.; GRAVESDEAL, R. WEISSMAN, B.E.; MOSES, H.L. Selective inhibition of growth-related gene expression in murine keratinocytes by transforming growth factor b. Mol. Cell Biol., v. 8, p. 3088-3093, 1988.

COLLER, B. S. Platelets in cardiovascular thrombosis and thrombolysis. In: FOZZARD H.A.; HABER E; JENNINGS R.B.; KATEZ A.M.; MORGAN H.E. The heart and cardiovascular system: scientific foundations. 2. ed. New York: Haven, 1992. v. 1, p. 219-273.

COMOGLIO, P.M.; BOCCACCIO, C. Scatter factors and invasive growth. Semin. Cancer Biol. v. 11, p. 153-165, 2001.
CONTRAN, R S.; KUMAR, V.; COLLINS, T. Robbins: Patologia estrutural e funcional. Rio de Janeiro: Guanabara Koogan, 2001. p. 44-100.

CONSTATINOU, J.; REYNOLDS, M.L.; WOOLF, C.J.; SAFIEH-GARABEDIAN, B.; FITZGERALD, $\mathrm{M}$. Nerve growth factor levels in developing rat skin: up regulation following skin wounding. Neuroreport, v. 5 , p. 2281-2284, 1994.

COWIN, A.J.; KALLINCOS, N.; HATZIRODOS, N.; ROBERTSON, J.G.; PICKERING, K.J.; COUPER, J.; BELFORD, D.A. Hepatocyte growth factor and macrophage-stimulating protein are up regulated during excisional wound repair in rats. Cell Tissue Res., v. 306, p. 239-250, 2001.

CRIBBS, R.K.; HARDING, P.A.; LUQUETTE, M.H.; BESNER, G.E. Endogenous production of heparinbinding EGF-like growth factor during murine partialthickness burn wound healing. J. Burn Care Rehabil., 23, p. 116-125, 2002.

D'SOUZA, P.J.; PAJAK, A.; BALAZSI, K.; DAGNINO, L. $\mathrm{Ca}+2$ and $\mathrm{BMP}-6$ signaling regulate $\mathrm{E} 2 \mathrm{~F}$ during epidermal keratinocyte differentiation. J. Biol. Chem., v. 276, p. 23531-23538, 2001.

DANILENKO, D.M.; RING, B.D.; TARPLEY, J.E.; MORRIS, B.; VAN, G.Y.; MORAWIECKI, A.; CALLAHAN, W:; GOLDENBER,GM.; HERSHENSON, S.; PIERCE, G.F. Growth factors in porcine full and partial thickness burn repair. Differing targets and effects of keratinocyte growth factor, platelet-derived growth factor-BB, epidermal growth factor, and neu differentiation factor. Am. J. Pathol., v. 147, p. 1261-1277, 1995.

DAVIES M. J.A macro and micro view of coronary vascular insult in ischemic heart disease. Circulation, v. 82, p.II-38 - II-46, 1990.

DESMOULIERE, A.; GEINOZ, A.; GABBIANI, F.; GABBIANI, G. Transforming growth factor-beta 1 induces alpha-smooth muscle actin expression in granulation tissue myifibroblasts and in quiescent and growing cultured fibroblasts. J. Cell Biol., v. 122, p. $103-$ 111, 1993. 
DEVALARAJA, R.M.; NANNEY, L.B.; QIAN, Q.; DU, J.; YU, Y.; DEVALARAJA, M.N.; RICHMOND, A. Delayed Wound healing in CXCR2 knockout mice. $J$. Invest. Dermatol., v. 115, p. 234-244, 2000.

Di PIETRO, L.A. Wound healing: the role of the macrophage and other immune cells. Shock, v. 4, p. 233-240, 1995.

DIPIETRO L.A.; BURDICK, M., LOW, Q.E.; KUNKEL, S.L.; STRIETER, R.M. MIP1alpha as a critical macrophage chemo attractant in murine wound repair. $J$. Clin. Invest., v. 101, p. 1693-1698, 1998.

DIPIETRO, L.A.; POLVERINI, P.J.; RAHBE, S.M.; KOVACS, E.J. Modulation of JE/MCP-1 expression in dermal wound repair. Am. J. Pathol., v. 146, p. 868-875, 1995.

DIPIETRO, L.A.; REINTJES, M.G.; LOW, Q.E.; LEVI, B.; GAMELLI, R.L. Modulation of macrophage recruitment into wounds by monocyte chemo attractant protein-1 . Wound Repair Regen., v. 9, p. 28-33, 2001.

ECKERSLEY, J. R. T.; DUDLEY, H. A. F. Wound and wound healing. British Medical Bulletin, v. 44, n. 2, p. 423-36, 1988.

ENGELHARD, E.; TOKSOY, A.; GOOBELER, M.; DEBUS, S.; BRÜCKER, E. B.; GILLITZER, R. Chemokines IL-8, Groa, MCP-1, IP-10, and Mig are sequentially and differentially expressed during phasespecific infiltration of leucocyte subsets in human wound healing. Am. J.Pathol., v.153, p. 1849-1860, 1998.

FAILLA, C.M; ODORISTO, T.; CIANFARANI, F.; SCHIETROMA, C.; PUDDU, P.; ZAMBRUNO, G. Placenta growth factor is induced in human keratinocytes during wound healing. J. Invest. Dermatol., v. 115, p. 388395,2000 .

FOXMAN, E. F.; CAMPBELL, J. J.; BUTCCHER, E. Multistep navigation and combinatorial control of leukocyte chemotaxis. J. Cell Biol., v. 139, p. 1349$1360,1997$.

FRANK, S.; HÜBNER, G.; BREIER, G.; LONGAKER, M.T.; GREENHALGH, D.G.; WERNER, S. Regulation of vascular endothelial growth factor expression in cultured keratinocytes: implications for normal and impaired wound healing. J. Biol. Chem., v. 270, p. 12607126013, 1995.
FRANK, S.; STALLMEYER, B.; KAMPFER, H.; KOLB, N.; PFEILSCHIFTER, J. Leptin enhances wound reepithelialization and constitutes a direct function of leptin in skin repair. : J. Clin. Invest. v. 106, p. 501-509, 2000.

FRAZIER, K.; WILLIAMS, S.; KOTHAPALLI, D.; KLAPPER, H.; GROTENDORST, G.R. Stimulation of fibroblast cell growth, matrix production, and granulation tissue formation by connective tissue growth factor. $J$. Invest. Dermatol., v. 107, p. 404-411, 1996.

GABBIANI, G.; RAYAN, G. B.; MAJNO, G. Presence of modified fribroblats in granulation tissue and possible role in wound contraction. Experientia, v. 27, n. 5 p. 549-550, 1970.

GAHARY, A.; SHEN, Y.J.; NEDELEC, B.; SCOTT, P.G.; TREDGET, E.E. Enhanced expression of RNAm for insulin like growth factor-1 in post-burn hipertrophic scar tissue and its fibrogenic role by dermal fibroblasts. Mol. Cell Biochem., v. 148, p. 25-32, 1995.

GAILIT, J.; WELCH, M.P.; CARK, R.A. TGF-beta 1 stimulates expression on keratinocytes integrins during reepithelialization of cutaneous wound. J. Invest. Dermatol., v. 103, p. 221-227, 1994.

GALE, N.W. ; YANCOPOULOS, G.D. Growth factors acting via endothelial cell-specific receptor tyrosine kinases: VEGFs, angiopoietins and ephrins in vascular development. Genes Dev., v.13, p. 1055-1066, 1999.

GALLUCCI, R.M.; SIMEONOVA, P.P.; MATHESON, J.M.; KOMMINENI, C.; GURIEL, J.L.; SUGAWARA, T.; LUSTER, M.I. Impaired cutaneous wound healing in interleukin-6-deficient and immunosuppressed mice. FASEB J. v.14, p. 2525-2531, 2000.

GARTNER, M.H.; BENSON, J.D.; CALDWELL, M.D. Insulin like growth factors I and II expression in the healing wound. J. Surg. Res., v. 52, p. 389-394, 1992.

GERSZTEN, R. E.; GARCIA-ZEPEDA, E. A.; LIM, Y. C.; YOSHIDA, M.; DING, H. A.; GIMBRONE, M. A.; LUSTER, A. D.; LUSCINSKAS, F. W.; ROSENZWEIG, A. MCP-1 and IL-8 trigger firm adhesion of monocytes to vascular endothelium under flow conditions. Nature, v. 398, p. 718-723, 1999. 
GIBRAN, N.S.; ISIK F.F.; HEIMBACH, D.M.; GRODON, D.; Basic fibroblast growth factor in the early human burn wound. J. Surg. Res. v. 56, p. 226-234, 1994.

GOEBELER, M.; YOSHIMURA, T.; TOKSOY, A.; RITTER, U.; BRÜCKER, E. B.; GILLITZER, R. The chemokine repertoire of human dermal microvascular endothelial cells and its regulation by inflammatory cytokines. J. Investig. Dermatol., v. 108, p. 445-451, 1998.

GREENHALGH, D.G. The role of growth factors in wound healing. J. Trauma., v. 41, p. 159-167, 1996.

GROTENDORST, G.R.; SOMA, Y.; TAKEHARA, K.; CHARETTE, M. EGF and TGF-alpha are potent chemoattractants for endothelial cells and EGF-like peptides are present at sites of tissue regeneration. J. Cell Physiol. v. 139, p. 617-623, 1989.

GROVES, R.W.; SCHMIDT-LUCKE, J.A. Recombinant human GM-CSF in the treatment of poorly healing wounds. Adv. Skin Wound Care., v. 13, p. 107-112, 2000.

GUIDUGLI-NETO, J. The effect of roentgen radiation on the capillary sprontsonal superficial loops of granulation tissue I: quantitative study of the vascular volume. Rev. Odontol. Univ. São Paulo, v. 1, p. 6-8, 1987.

GUIDUGLI-NETO, J. The effect of roentgen radiation on the capillary sprontsonal superficial loops of granulation tissue II: ultrastructural aspects. Rev. Odontol. Univ. São Paulo, v. 6, 66-71, 1992.

GUO, L.; DEGENSTEIN, L.; FUCHS, E. Keratinocyte growth factor is required for hair development but not for wound healing. Genes Dev., v. 10, p. 165-175, 1996.

HARRIS, I.R.; YEE, K.C.; WALTERS, C.E.; CUNLIFFE, W.J.; KEARNEY, J.N.; WOOD, E.J.; INGHAM, E. Cytokine and protease levels in healing and non-healing chronic venous leg ulcers. Exp. Dermatol., v. 4, p. 342349; 1995.

HARSUM, S.; CLARKE, J.D.; MARTIN, P. A reciprocal relationship between cutaneous nerves and repairing skin wounds in the developing chick embryo. Dev. Biol., v. 238, p. 27-29, 2001.
HASAN, W.; ZHANG, R.; LU, M.; WARN, J.D.; SMITH, P.G; Coordinate expression of NGF and a-smooth muscle actin RNAm and protein in cutaneous wound tissue of developing and adult rats. Cell Tissue Res., v. 300, p. 97109,2000 .

HELDIN, C.H.; ERIKSSON, U.; OSTMAN, A. New members of the plateled-derived growth factor family of mitogens. Arch. Biochem. Biophys., v. 398, p.284-290, 2002.

HELDIN, C.H.; WESTRMARK, B.; Mechanism of action and in vivo role of plateled-derived growth facto. Physiol. Rev., v. 79, p. 1283-1316, 1999.

HOWDIESHELL, T.R.; CALLAWAY, D.; WEBB, W.L.; GAINES, M.D.; PROCTER, C.D. Jr.; SATHYANARAYANA POLLOCK, J.S.; BROCK, T.L.; McNEIL, P.L. Antibody neutralization of vascular endothelial growth factor inhibits wound granulation tissue formation. J. Sur. Res., v. 96, p. 163-182, 2001.

HUANG, J.S.; WANG, Y.H.; LING, T.Y.; CHUANG, S.S.; JOHNSON, F.E.; HUANG, S.S. Synthetic TGF-beta antagonist accelerates wound healing and reduces scarring. FASEB J., v. 16, p. 1269-1270, 2002.

HUBNER, G.; HU, Q.; SMOLA, H.; WERNER, S. Strong induction of activin expression after injury suggests an important role of activin in wound repair. Dev. Biol., v. 173, p. 490-498, 1996.

HUTSON, J.M.; NIALL, M. EVANS, D.; FOWLER R. Effect of salivary glands on wound contraction in mice. Nature, v. 279, p. 793-795, 1979.

HUYBRECHTS-GODIN, G.; PEETER-JORIS, C.; VAES, G. Macrophage-fibroblast interaction in collagenase production and cartilage degration. Biochem. J., v. 184, p. 643-650, 1979.

IGARASHI, A.; OKOCHI, H.; BRADHAM, D.M.; GROTENDORST, G.R. Regulation of connective tissue growth factor gene expression in human skin fibroblast and during wound repair. Mol. Cell Biol., v. 4, p. 637-645, 1993.

JENNINGS, L.K.; PHILLIPS, D. R. Purification of GP IIb/ IIIa from human platelet plasma membranes and characterization of a calcium - dependent GP IIb/IIIa complex. J. Biol. Chen., v. 257, p. 10458-10456, 1982. 
JENNISCHE, E.; SKOTTNER, A.; HANSSON, H.A. Dynamic changes in insulin like growth factor immunoreactivity correlate to repair events in rat ear after freeze-thaw injury. Exp. Mol. Pathol., v. 47, p. 193-201, 1987.

JOHNSTON, D. E. Wonnd healing in skin. Veterinary Clinics of North America: small animal practica, v. 20, n.1,p. 1-25, 1990.

JONES, S. A.; WOLF, M.; QIN, S.; MACKAY, C. R.; BAGGIOLINI, M. Different functions for the interleukin 8 receptors (IL-8R) of human neutrophil leukocytes: NADPDH oxidase and phospholipase D are activated through IL-8R1 but not IL-8R2. Proc. Natl. Acad. Sci. USA., v. 93, p. 6682-6686, 1996.

KAISER, S.; SCHIRMACHER, P.; PHILIPP, A.; PROTSCHKA, M.; MOLL, I.; NICOL, K.; BLESSING, M. Induction of bone morphogenetic protein6 in skin wounds. Delayed reepitheliazation and scar formation in BMP-6 overexpressing transgenic mice. $J$. Invest. Dermatol., v. 111, p. 1145-1152, 1998.

KAWADA, A.; HIRUMA, M.; NOGUCHI, H.; ISHIBASHI, A.; MOTOYOSHI, K.; KAWADA, I. Granulocyte and macrophage colony-stimulating factors stimulate proliferation of human keratinocytes. Arch. Dermatol. Res., v. 289, p. 600-602, 1997.

KIBE, Y.; TAKENAKA, H.; KISHIMOTO, S. Spatial and temporal expression of basic fibroblast growth factor protein during wound healing of rat skin. Br. J. Dermatol., v. 143, p. $720-727,2000$.

KIREEVA, M.L.; MO, F.E.; YANG, G.P.; LAU, L.F. Cyr61, a product of growth factor-inducible immediate-early gene, promotes cell proliferation, migration, and adhesion. Mol. Cell Biol., v.16, p. 1326-1334, 1996.

KNIGHTON, D. R.; SILVER, I.; HUNT, T. K. Regulation of wound-healing angiogenesis-effect of oxygen gradients and inspired oxygen concentration. Surgery, v.90, p. 262270, 1981.

KOTHAPALLI, D.; FRAZIER, K.S.; WELPLY, A.; SEGARINI, P.R.; GROTENDORST, G.R. Transforming growth factor $b$ induce anchorage-independent growth of NRK fibroblast via a connective tissue growth factor dependent signaling pathway. Cell Growth Differ., v. 8, p. 61-68, 1997.
KURITA, Y.; TSUBOI, R.; UEKI, R.; RIFKIN, D.B.; OGAWA, H. Immunohistochemical localization of basic fibroblast growth factor in wound healing sites of mouse skin. Arch. Dermatol. Res., v. 284, p. 193-197, 1992.

LAUER, G.; SOLLBERG, S.; COLE, M.; FLAMME, I.; STURZEBECHER, J.; MANN, K.; KRIEG, T.; EMING, S.A. Expression and proteolysis of vascular endothelial growth factor is increased in chronic wound. J. Invest. Dermatol., v. 115, p. 12-18, 2000.

LEFKOVITS J; PLOW, E.F.; TOPOL, E. J. Platelet glycoprotein Ilb/IIIa receptors in cardiovascular medicine. N. Engl. J. Med., v. 332, p. 1553-1559, 1995.

LEWIN, G.R.; MENDELL, L.M. nerve growth factor and nociception. Trends Neurosci., v. 16, p. 353-359, 1993.

LI, A.K.; KOROLY, M.J.; SCHATTENNERK, M.E.; MALT, R.A.; YOUNG, M. Nerve growth factor: acceleration of the rate of wound healing in mice. Proc. Natl. Acad. Sci. USA., v. 77, p. 4379-4381, 1980.

LOW, Q.E.; DRUGEA, I.A.; DUFFNER, L.A.; QUINN, D.G.; COOK, D.N.; ROLLINS, B.J.; KOVACS, E.J.; DIPIETRO, L.A. Wound healing in MIP-1alpha(-/-) and MCP-1(-/-) mice. Am. J. Pathol., v. 159, p. 457-463, 2001.

LUSTER, A.D.; CARDIFF, R.D.; MACLEAN, J.A.; CROWE, K.; GRANSTEIN, R.D. Delayed wound healing and disorganized neovascularization in transgenic mice expressing the IP-19 chemokine. Proc. Assoc. Am. Physicians., v. 110, p. 183-196, 1988.

LYNCH, S.E.; COLVIN, R.B.; ANTONIADES, H.N. Growth factors in wound healing. Single and siynergistic effects on partial thickness porcine skin wounds. J. Clin. Invest. v. 84, p. 640-646, 1989.

MAJNO, G.; JORIS, I. Cells, tissues and disease: principles of general pathology. Cambridge: Blackwell Science, $1996.974 \mathrm{p}$.

MANN, A.; BREUHAHN, K.; SCHIRMACHER, P.; BLESSING, M. Keratinocyte derived granulocytemacrophage colony stimulating factor accelerates wound healing: stimulation of keratinocyte proliferation, granulation tissue formation and vascularization. J. Invest. Dermatol., v. 117, p. 1382-1390, 2001. 
MARCHESE, C.; CHEDID, M.; DIRSCH, O.R.; CSAKY, K.G.; SANTANELLI, F.; LATINI, C.; LAROCHELLE, W.J.; TORRISI, M.R.; AARONSON, S.A. Modulation of keratinocyte growth factor and its receptor in reepithelialising human skin. J. Exp. Med., v. 182, p. 13691376, 1995.

MARIKOVSKY, M.; BREUING, K.; LIU, P.Y.; ERIKSSON, E.; HIGASHIYAMA, S.; FARBER, P.; ABRAHAM, J.; KLAGSBRUN, M. Apperance of heparin-binding EGF-like growth factor in wound fluid as a response to injury. Proc. Natl. Aca. Sci. USA., v.90, p. 3889-3893, 1993.

MARIKOVSKY, M.; VOGT, P.; ERIKSSON, E.; RUBIN, J.S.; TAYLOR, W.G.; JOACHIM, S.; KLAGSBRUN, M. Wound fluid-derived heparin-binding EGF-like growth factor (HB-EGF) is synergistic with insulin-like growth factor-I for Balb/MK keratinocyte proliferation. J. Invest. Dermatol., v. 106, p. 616-621, 1996.

MASSAGUÉ, J. TGF-beta signal transduction. Annu. Rev. Biochem., v. 67, p. 753-791, 1998.

MASSAGUÉ, J. The transforming growth factor-beta family. Annu. Rev. Cell Biol., v. 6, p. 597-641, 1990.

MATSUDA, H.; KOYAMA, H.; SATO, H.; SAWADA, J.; ITAKURA, A.; TANAKA, A.; MATSUMOTO, M.; KONNO, K.; USHIO, H.; MATSUDA, K. Role of nerve growth factor in cutaneous wound healing: accelerating effects in normal and healing-impaired diabetic mice. J. Exp. Med. v. 187, p. 297-306, 1998.

MATSUOKA, J.; GROTENDORST, G.R. Two peptides related to platelet-derived growth factor are present in human wound fluid. Proc. natl. Acad. Sci. USA., v. 86, p. 4416-4420, 1989.

MCDONNELL, M.A.; LAW, B.K.; SERRA, R.; MOSES, H.L. Antagonistic effects of TGFbeta1 and BMP-6 on skin keratinocyte differentiation. Exp Cell Res., v. 263, p. 265-273, 2001.

MICERA, A.; VIGNETI, E.; PICKHOLTZ, D.; REICH, R.; PAPPO, O.; BONINI, S.; MAQUART, F.X.; ALOE, L.; LEVI-SCHAFFER, F. Nerve growth factor displays stimulatory effects on human skin and lung fibroblasts, demonstrating a direct role for this factor in tissue repair. Proc. Natl. Acad. Sci. USA., v. 98, p. 6162-6167, 2001.
MONTESANO, R.; ORCI, L. Transforming growth factor b stimulates collagen-matrix contraction by fibroblasts: imolications for wound healing. Proc. Natl. Acad. Sci. USA., v.85, p. 4894-4897, 1988.

MOORE, K.W.; DE WAAL MALEFYT, R.; COFFMAN, RL.; O'GARRA, A. Interleukin-10 and the interleukin-10 receptor. Annu. Rev. Immunol., v. 19, p. 683-765, 2001.

MORI, R.; KONDO, T.; OHSHIMA, T.; ISHIDA, Y.; MUKAIDA, N. Accelerated wound healing in tumor necrosis factor receptor $\mathrm{p} 55$-deficient mice with reduced leukocyte infiltration. FASEB J., v. 16, p. 963-974, 2002.

MUNZ, B.; SMOLA, H.; ENGELHARDT, F.; BLEUEL, K.; BRAUCHLE, M.; LEIN, I.; EVANS, L.W.; HUYLEBROECK, D.; BALLING, R.; WERNER, S. Overexpression of activin $A$ in the skin of transgenic mice reveals new activities of activin in epidermal morphogenesis, dermal fibrosis and wound repair. EMBO J., v. 18, p. 5205-5205, 1999.

MURDOCH, C.; FINN, A. Chemokine receptors and their role in inflammation and infectious diseases. Blood, v. 95, p. 3032-3043, 2000.

NEWMAN, S. L.; HENSON, J. E.; HENSON, P. M. Phagocytosis of senescent neutrophils by human monocyte derived macrophages and rabbit inflammatoty macrophages. J. Exp. Med., v. 156, p. 430-442, 1992.

O'DELL, S.D.; DAY, I.N.M. Molecules in focus: insulin-like growth factor II (IGF-II). Int. J. Biochem. Cell Biol., v. 30, p. 767-771, 1998.

OHSHIMA, T.; SATO, Y. Time-dependent expression of interleukin-10 (IL-10) mRNA during the early phase of skin wound healing as a possible indicator of wound vitality. Int. J. Legal Med., v. 111, p. 251-255, 1998.

ONO, I.; GUNJI, H.; ZHANG, J.Z.; MARUYAMA, K.; KANEKO, F. Studies on cytokines related to wound healing in dono site wound fluid. J. Dermatol. Sci., v. 10, p. 241-245, 1995.

ORNITZ, D.M. FGFs heparan sulfate and FGFRs: complex interactions essential for development. Bioassays, v. 22, p. 108-112, 2000.

ORNITZ, D.M.; ITOH, N. Fibroblast growth factors. Genome Biol., v. 2, p. 3005.1-3005.12, 2001. 
PEACOCK JR., E. E. The wound repair. Philadelphia: W B Saunders, 1984. p. 76-85.

PETERS, K.G.; DEVRIES, C.; WILLIAMS, L.T. Vascular endothelial growth factor receptor expression during embryogenesis and tissue repair suggests a role in endothelial differentiation and blood vessel growth. Proc. Natl. Acad. Sci. USA., v. 90, p. 8915-8919, 1993.

PINCELLI, C. Nerve growth factor and keratinocytes: a role in psoriasis. Eur. J. Dermatol., v. 10, p. 85-90, 2000.

RAPPOLEE, D.A.; MARK, D.; BANDA, M.J.; WERB, Z. Wound macrophages express TGF-alpha and other growth factors in vivo: analysis by mRNA phenotyping. Science, v. 241, p. 708-712, 1988.

RAYCHAUDHURI, S.K.; RAYCHAUDHURI, S.P.; WELTMAN, H.; FARBER, E.M. Effect of nerve growth factor on endothelial cell biology: proliferation and adherence molecule expression on human dermal microvascular endothelial cells. Arch. Dermatol. Res., v. 293, p. 291-295, 2001.

RENNEKAMPFF, H.O.; HANSBROUGH, J.F.; KIESSIG, V.; DORE, C.; STICHERLING, M.; SCHARODER, J.M. Bioactive interleukin- 8 is expressed in wounds and enchances wound healing. J. Surg. Res., v. 93, p. 41-54, 2000 .

RENNEKAMPFF, H.O.; HANSBROUGH, J.F.; WOODSM V. JR.; DORE, C.; KIESSIG, V.; SCHRODER, J.M. Role of melanoma growth stimulatory activity (MGSA/gro) on keratinocyte function in wound healing. Arch. Dermatol. Res., v. 289, p. 204-112, 1997.

REYNOLDS, M.; ALVARES, D.; MIDDLETON, J.; FITZGERALD, M. Neonatally wounded skin induces NGF-independent sensory neurite out-growth in vitro. Brain Res., v. 102, p. 275-283, 1997.

RICHES, D. W. Macrophage involvement in wound repair, remodeling and fibrosis. In: CLARK, R. A. F., (Ed.) The molecular and cellular biology of wound repair. 2. ed. New York: Plenum, 1996, p. 143-168.

RING, B.D.; SCULLY, S.; DAVIS, C.R.; BAKER, M.B.; CULLEN, M.J.; PELLEYMOUNTER, M.A.; DANILENKO, D.M. Systemically and topically administered leptin both accelerate wound healing in diabetic ob/ob mice. Endocrinology, v. 141, p. 446-449, 2000.
RISAU, W. Angiogenic growth factors. Prog. Growth Factor Res., v. 2, p. 71-79, 1990.

ROBERTS, A.B. Molecular and cell biology of TGF-beta. Miner Electrolyte Metab. v. 24, p. 111-119, 1998.

ROBERTS, A.B.; SPORN, M.B. Transforming growth factor-b. In: The Molecular and Cellular Biology of Wound Repair. 2 ed. New York: Plenum, 1996, p. 275-308.

ROBERTS, A.B.; SPORN, M.B.; ASSOIAN, R.K.; SMITH, J.M.; ROCHE, N.S.; WAKE-FIELD, L.M.; HEINE, U.I.; LIOTTA, L.A.; FALANGA, V.; KEHRL, J.H.; FAUCI, A.S. Transforming growth factor type beta: rapid induction of fibrosis and angiogenesis in vivo and stimulation of collagen formation in vitro. Proc. Natl. Acad. Sci. USA., v. 83, p. 4167-4171, 1986.

ROBERTSON, J.G.; BELFORD, D.A.; BALLARD, F.J. Clearance of IGFs and insulin from wounds: effect of IGF-binding proteins interactions. Am. J. Physiol. Endocrinol. Metab., v. 276, p. E663-E671, 1999.

ROSSI, D.; ZLOTNIK, A. The biology of chemokines and their receptors. Annu. Rev. Immunol., v. 18, p. 217-242, 2000.

RUDOLPH, R.; BALLANTYNE JR., D. L. Skin grafts. In: McCARTHY, J. G.; MAY JR., J. W.; LITTLER, J. W. Plastic surgery. v. 1, p. 221-267. Philadelphia: WB Saunders, 1990.

SATO, M.; SAWAMURA, D.; INA, S.; YAGUCHI, T.; HANADA, K.; HASHIMOTO, I. In vivo introduction of the interleukin 6 gene into human keratinocyte: induction of epidermal proliferation by the fully spliced form of interleukin 6, but, not by the alternatively spliced form. Arch. Dermatol. Res., v. 291, p. 400-404, 1999.

SATO, Y.; OHSHIMA, T.; KONTO, T. Regulatory role of endogenous interleukin-10 in cutaneous inflamatory response of murine wound healing. Biochem. Biophys. Res. Commum., v. 256, p. 194-199, 1999.

SCHULTZ, G.S.; WHITE, M.; MITCHELL, R.; BROWN, G.; LYNCH, J.; TWARDZIK, D.R.; TODARO, G.J. Epithelial wound healing enhanced by transforming growth factor-alpha and vaccinia growth factor. Science, v. 235, p. 350-352, 1987. 
SEISHIMA, M.; NOJIRI, M.; ESAKI, C.; YONEDA, K.; ETO, Y.; KITAJIMA, Y. Activin A induces terminal differentiation of cultured human keratinocyte. J. Invest. Dermatol., v. 112, p. 432-436, 1999.

SELLHEYER, K.; BICKNBACH, J.R.; ROTHNAGEL, J.A.; BUNDMAN, D.; LONGLEY, M.A.; KRIEG, T.; ROCHE, N.S.; ROBERTS, A.B.; ROOP, D.R. Inhibition of skin development by overexpression of transforming growth factor b1 in the epidrmis of transgenic mice. Proc. Natl. Acada. Sci. USA., v. 90, p. 5237-5241, 1993.

SHAH, M.; FOREMAN, D.M.; FERGUSON, M.W. Neutralisation of TGF-beta 1 and TGF-beta 2 or exogenous addition of TGF-beta 3 to cutaneous rat wounds reduces scarring. J. Cell Sci., v. 108, p. 985$1002,1995$.

SHAH, M.; FOREMAN, D.M.; FERGUSON, M.W. Neutralising antibody to TGF-beta 1,2 reduces cutaneous scarring in adult rodents. J. Cell Sci., v. 107, p. 1137-1157, 1994.

SHIMIZU, A.; KATO, M.; NAKAO, A.; IMAMURA, T.; TEN DIJKE, P.; HELDIN, C.H.; KAWABATA, M. SHIMADA, S.; MIYAZONO, K.; Identification of receptors and Smad proteins involved in activin signaling in a human epidermal keratinocyte cell line. Genes Cells, v. 3, p. 125-134, 1998.

SHIMO, T.; NAKANISHI, T.; NISHIDA, T.; ASANO, M.; KANYAMA, M.; KUBOKI, T.; TAMATANI, T.; TEZUKA, K.; TAKEMURA, M.; MATSUMURA, T.; TAKIGAWA, M. Connective tissue growth factor induces the proliferation, migration, and tube formation of vascular endothelial cells in vitro, and angiogenesis in vivo. J. Biochem., v. 126, p. 137-145, 1999.

SHIRAHA, H.; GLADING, A.; GUPTA, K.; WELLS, A. IP-10 inhibits epidermal growth factor-induced motility by decreasing epidermal growth factor receptor-mediated calpain activity. J. Cell Biol., v. 146, p. 243-254, 1999.

SINGER, A. J.; CLARK, R. A. F. Cutaneous wound healing. New Engl. J. Med., 341, p. 738-746, 1999.

SOMA, Y.; DVONCH, V.; GROTENDORST, G.R. Platelet-derived growth factor AA homodimer is the predominant isoform in human platelets and acute human wound fluid. FASEB J., v.6, p. 2996-3001, 1992.
STALLMEYER, B.; PFEILSCHIFTER, J.; FRANK, S. Systemically and topically supplemented leptin fails to reconstitute a normal angiogenic response during skin repair in diabetic ob/ob mice. Diabetologia, v. 44, p. 471479, 2001.

STEED, D.L. Modifying the wound healing response with exogenous growth factors. Clin. Plast. Surg., v. 25, p. 397-405, 1998.

STEENFOS, H.H.; JANSSON, J.O. Gene expression of insulin-like growth factor-I and IGF-I receptor during wound healing in rats. EurJSurg. v. 158, p. 327-331, 1992.

STRACHAN, L.; MURISON, J.G.; PRESTIDGE, R.L.; SLEEMAN, M.A.; WATSON, J.D.; KUMBLE, K.D. Cloning and biological activity of epigen, a novel member of the epidermal growth factor superfamily. J. Biol. Chem., v. 276, p. 18265-18271, 2001.

STRIETER, R. M.; POLVERINI, P. J.; KUNKEL, S. L.; ARENBERG, D. A.; BURDICK, M. D.; KASPER, J.; WALZ, A.; MARRIOT, D.; CHAN, S. Y.; ROCZNIAK, S.; SHANAFELT, A. B. The functional role of the ELR motif in chemokine-mediated angiogenesis. J. Biol. Chem., v.270, p.27348-27357, 1995.

TODD, R.; DONOFF, B.R.; CHIANG, T.; CHOU, M.Y.; ELOVIC, A.; GALLAGHER, G.T.; WONG, D.T. The eosinophil as a cellular source of transforming growth factor alpha in healing cutaneous wounds. Am. J. Pathol., v. 138 , p. 1307-1313, 1991.

TRENGOVE, N.J.; BIELEFELDT-OHMSNN, H.; STACEY, M.C. Mitogenic activity and cytokine levels in non-healing and healing chronic leg ulcers. Wound Repair Regen. v. 8, p. 13-25, 2000.

TZAHAR, E.; MOYER, J.D.; WATERMAN, H.; BARBACCI, E.G.; BAO, J.; LEVKOWITZ, G.; SHELLY, M.; STRANO, S.; PINKAS-KRAMARSKI, R.; PIERCE, J.H.; ANDREWS, G.C.; YARDEN, Y. Pathogenic poxviruses reveal viral strategies to exploit the ErbB signaling network. EMBO J. v. 17, p. 5948-5963, 1998.

VOGT, P.M.; LEHNHARDT, M.; WAGNER, D.; JENSEN, V.; KRIEG, M.; STEINAU, H.U. Determination of endogenous growth factors in human wound fluid: temporal presence and profiles of secretion. Plast. Reconstr. Surg., v. 102, p. 117-123, 1998. 
WAGNER CL; MASCELLI M. A; NEBLOCK DS; WEISMAN HF; COLLER BS; JORDAN RE. Analysis of GP IIb/IIIa receptor number by quantification of 7E3 binding to human platelets. Blood, v. 88, p. 907-914, 1996.

WANKELL, M.; KAESLER, S.; ZHANG, Y.Q.; FLORENCE, C.; WERNER, S.; DUAN R. The activin binding proteins follistatin and follistatin-related protein are differentially regulated in vitro and during cutaneous wound repair. J. Endocrinol., v. 171, p. 385-395, 2001.

WENER, S. Keratinocyte growth factor: a unique player in epithelial repair processes. Cytokine Growth Factor Rev., v. 2, p. 153-165, 1998

WENER, S.; PETERS, K.G.; LONGAKER, M.T.; FULLER-PACE, F.; BANDA, M.; WILLIAMS, L.T. Large induction of keratinocyte growth factor expression in the dermis during wound healing. Proc. Natl. Acad. Sci. USA., v. 89, p. 6896-6900, 1992.

WILLERSON, J. T. Conversion from chronic to acute coronary heart disease sindromys. Role of platelets and platelet products. Tex. Heart Inst. J., v. 22, p. 13-19, 1995.
WONG, D.T.; DONOFF, R.B.; YANG, J.; SONG, B.Z.; MATOSSIAN, K.; NAGURA, N.; ELOVIC, A.; MCBRIDE, J.; GALLAGHER, G.; TODD, R. et al. Sequential expression of transforming growth factors alpha and beta 1 by eosinophils during cutaneous wound healing in the hamster. Am. J. Pathol., v. 143, p. 130-142, 1993.

YARDEN, Y. The EGFR family and its ligands in human cancer. signalling mechanisms and therapeutic opportunities. Eur. J. Cancer., v. 37, p. S3-8, 2001.

ZAMBRUNO, G.; MARCHISIO, P.C.; MARCONI, A.; MELCHIORI, A.; GIANNTTI, A.; DE LUCA, M. Transforming growth factor-beta 1 modulates beta 1 and beta 5 integrin receptors and induces the de novo expression of the alpha $\mathrm{v}$ beta 6 heterodimer in normal human keratinocytes: implications for wound healing. $J$. Cell Biol., v. 129, p. 853-865, 1995.

Recebido para publicação em 19 de outubro de 2004. Aceito para publicação em 10 de fevereiro de 2005. 